Quim. Nova, Vol. 35, No. 11, 2194-2201, 2012

\title{
METABÓLITOS SECUNDÁRIOS DOS NUDIBRÂNQUIOS Tambja stegosauriformis, Hypselodoris lajensis E Okenia zoobotryon E DOS briozoários Zoobotryon verticillatum E Bugula dentata DA COSTA DO BRASIL ${ }^{\#}$
}

\author{
Fábio R. Pereira e Roberto G. S. Berlinck* \\ Instituto de Química de São Carlos, Universidade de São Paulo, CP 780, 13560-970 São Carlos - SP, Brasil \\ Edson Rodrigues Filho, Katyuscya Veloso e Antonio G. Ferreira \\ Departamento de Química, Universidade Federal de São Carlos, CP 676, 13560-970 São Carlos - SP, Brasil \\ Vinicius Padula \\ Zoologische Staatssammlung München, Mollusca Sektion, Münchhausenstr. 21, 81247, München, Germany
}

Recebido em 14/12/11; aceito em 19/7/12; publicado na web em 28/9/12

\begin{abstract}
SECONDARY METABOLITES FROM NUDIBRANCHS Tambja stegosauriformis, Hypselodoris lajenis AND Okenia zoobotryon AND FROM BRYOZOANS Zoobotryon verticillatum AND Bugula dentata FROM THE BRAZILIAN COASTLINE. The chemical investigation of the $\mathrm{MeOH}$ extract from the bryozoan B. dentata $\mathrm{MeOH}$ yielded tambjamines A (1), C (3), D (4), K (6), aldehyde 8 and the new tambjamine $\mathrm{J} 1(\mathbf{9})$, while the extract of its predator, the nudibranch Tambja stegosauriformis, yielded tambjamines $\mathrm{C}$ and $\mathrm{K}$, along with aldehyde 8. Furodisinin lactone (11) was isolated from the nudibranch Hypselodoris lajensis, a compound previously isolated from Dysidea sponges. The alkaloid 2,5,6-tribromo- $N$-methylgramine (12) was isolated from the nudibranch Okenia zoobotryon and from its prey, the bryozoan Zoobotryon verticillatum, the only source of $\mathbf{1 2}$ previously known.
\end{abstract}

Keywords: nudibranch; bryozoan; Tambja.

\section{INTRODUÇÃO}

Moluscos nudibrânquios são predadores de esponjas, ascídias, briozoários, octocorais e outros moluscos. ${ }^{1}$ Suas presas produzem ou acumulam substâncias que muitas vezes apresentam atividades biológicas. Nudibrânquios terminam por adquirir e acumular estas substâncias para sua própria defesa. Além disso, diversas espécies de nudibrânquios possuem a capacidade de biossintetizar produtos naturais de novo. ${ }^{2,3}$ Tais metabólitos secundários isolados de nudibrânquios apresentam diversas atividades biológicas, tais como antitumoral, ${ }^{4}$ antimicrobiana, ${ }^{5}$ antifúngica ${ }^{6}$ e citotóxica, ${ }^{7,8}$ associadas à ação defensiva destes produtos naturais.

Nudibrânquios do gênero Tambja apresentam tambjaminas, que são alcaloides pirrólicos já isolados de bactérias e outros invertebrados marinhos, como briozoários e ascídias. ${ }^{9,10}$ As tambjaminas parecem estar relacionadas com o mecanismo de defesa química de nudibrânquios do gênero Tambja. ${ }^{11}$ Uma série de derivados sintéticos de tambjaminas foi avaliada quanto à sua atividade antimicrobiana e, também, sua citotoxicidade frente a linhagens de células tumorais humanas. A maioria dos derivados de tambjaminas testados apresentou potente atividade antifúngica contra Malassezia furfur e atividade antiproliferativa não seletiva contra células de câncer e células normais humanas. Em particular, as tambjaminas I e J apresentaram efeito indutor de apoptose. ${ }^{12}$

Previamente realizamos a investigação química do nudibrânquio Tambja sp. (equivocadamente identificado como Tambja eliora), coletado em São Sebastião - SP, ${ }^{13}$ do qual foram isoladas as tambjaminas A (1) e D (4). Os efeitos citotóxicos e genotóxicos da tambjamina D foram analisados em uma linhagem de células de fibroblastos pulmonares de uma espécie de hamster. A substância apresentou atividade citotóxica frente a esta linhagem (V79), com $\mathrm{IC}_{50}$ de 1,2 $\mu \mathrm{g} / \mathrm{mL} .{ }^{14}$ Todavia, a espécie Tambja stegosauriformis ainda não havia sido objeto de estudo químico.

*e-mail: rgsberlinck@iqsc.usp.br

\#Artigo em homenagem ao Prof. Otto R. Gottlieb (31/8/1920-19/6/2011)
Hypselodoris lajensis (Troncoso, García e Urgorri, 1998) é um nudibrânquio membro da família Chromodorididae, um grupo de moluscos nudibrânquios que geralmente apresenta coloração aposemática, tipicamente uma estratégia de defesa. ${ }^{15}$ Estudo químicos realizados Hypselodoris mostraram que se utilizam de furanosesquiterpenos como defesa química. ${ }^{16,17}$ Como exemplo, a furodisinina foi isolada a partir do nudibrânquio Hypselodoris zebra (Heilprin, 1889) e da esponja marinha Dysidea etheria (De Laubenfels, 1936), da qual o molusco se alimenta. O nudibrânquio Hypselodoris lajensis também não havia sido objeto de investigação química.

Zoobotryon verticillatum (Delle Chiaje, 1828) é um briozoário considerado cosmopolita e potencialmente invasor ${ }^{18}$ conhecido por conter alcaloides bromados, como a 2,5,6-tribromo- $N$-metilgramina, ${ }^{19}$ que é uma substância de defesa do animal. ${ }^{19} \mathrm{O}$ nudibrânquio Okenia zoobotryon (Smallwood, 1910) encontra-se comumente associado à Zoobotryon verticillatum, vivendo, se alimentando e até se reproduzindo sobre o briozoário. ${ }^{18}$ Porém, ainda não haviam sido realizados estudos químicos com $O$. zoobotryon de forma a verificar se o nudibrânquio captura ou não substâncias de Z. verticillatum.

O objetivo principal deste trabalho foi verificar se os moluscos Tambja stegosauriformis, Hypselodoris lajensis e Okenia zoobotryon capturavam e acumulavam substâncias de suas presas, o briozoário Bugula dentata, a esponja Dysidea $\mathrm{sp} .{ }^{20}$ e o briozoário Zoobotryon verticillatum, respectivamente. Adicionalmente, verificar se os metabólitos presentes nas presas são assimilados no seu conjunto por seus predadores. Os resultados deste trabalho permitiram estabelecer as respostas para tais hipóteses. Este é o primeiro trabalho químico focado em espécies de nudibrânquios da costa brasileira e o primeiro a investigar quimicamente as espécies aqui estudadas.

\section{RESULTADOS E DISCUSSÃO}

Investigação química dos extratos do nudibrânquio Tambja stegosauriformis e do briozoário Bugula dentata

$\mathrm{O}$ extrato $\mathrm{MeOH}$ do nudibrânquio T. stegosauriformis foi 
submetido à separação por CLAE em fase reversa $\mathrm{C}_{18}$. As frações resultantes da cromatografia foram analisadas por CLAE-UV-EM. As tambjaminas apresentam espectros no ultravioleta característicos, com uma banda intensa entre 390 e 410 nm, em decorrência ao cromóforo bispirrólico. ${ }^{21}$ Dependendo dos substituintes no sistema bispirrólico, este cromóforo pode apresentar ligeiras variações dos comprimentos de onda nos máximos de absorção. Por exemplo, no caso das tambjaminas A (1) e B (2) (Figura 1), nas quais o grupo enamina não apresenta substituintes, os máximos de absorção $\left(\lambda_{\max }\right)$ das duas bandas do espectro no UV situam-se entre 250-255 e em $385 \mathrm{~nm}$. Já no caso de outras tambjaminas, que apresentam o grupo enamina substituído com diferentes grupos alquila, os máximos de absorção destas duas bandas situam-se acima de $255 \mathrm{~nm}$ e acima de $398 \mathrm{~nm}$. Além disso, diversas tambjaminas apresentam átomos de bromo em sua estrutura, o que pode auxiliar a análise de seus espectros de massas. ${ }^{22}$<smiles></smiles>

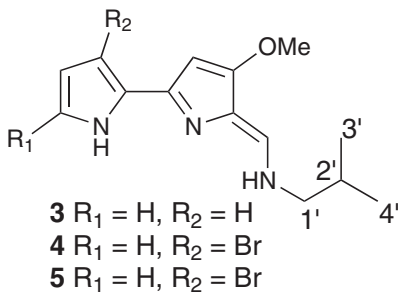<smiles>COC1=CC(c2ccc[nH]2)=N/C1=C\NCC(C)C</smiles><smiles>CCN/C=C1\N=C(c2ccc(Br)[nH]2)C=C1OC</smiles><smiles>[R]c1ccc(-c2cc(OC)c(C=O)[nH]2)[nH]1</smiles>

$7 \mathrm{R}=\mathrm{H}$

$$
10 \mathrm{R}_{1}=\mathrm{Br}, \mathrm{R}_{2}=\mathrm{H}
$$

Figura 1. Estruturas químicas das tambjaminas $A-D(1-4)$, tambjamina I (5), tambjamina $K(\mathbf{6})$, 4-metóxi-2,2'-bipirrol-5-carboxaldeído (7), 5'-bromo-4-metóxi-2,2'-bipirrol-5-carboxaldeído (8), tambjamina J1 (9), tambjamina $J(10)$ e tambjamina $G(\mathbf{1 1})$

A análise dos dados de UV-EM das frações do extrato $\mathrm{MeOH}$ de T. stegosauriformis indicou a presença das tambjaminas C (3) e K (6) (Figura 1), além dos aldeídos formados pela hidrólise das tambjaminas A (1) e B (2), o 4-metóxi-2,2'-bipirrol-5-carboxaldeído (7) e 5'-bromo-4-metóxi-2,2'-bipirrol-5-carboxaldeído (8) (Figura 1), respectivamente. Adicionalmente, observou-se a presença de uma substância exibindo no seu espectro de massas a presença de um átomo de bromo, devido à presença de dois íons $[\mathrm{M}+\mathrm{H}]^{+} \mathrm{em} \mathrm{m} / \mathrm{z}$ 324 e 326, com aproximadamente a mesma intensidade. Os dados observados nas análises por CLAE-UV-EM poderiam indicar a presença ou da tambjamina D (4) ou da tambjamina I (5) (Figura 1), uma vez que estas substâncias são isoméricas. A análise dos dados de $\mathrm{RMN}$ de ${ }^{1} \mathrm{H}$ obtidos para esta fração indicou que se tratava da tambjamina D (4). A principal diferença entre os espectros de RMN de ${ }^{1} \mathrm{H}$ das tambjaminas D e I está nos deslocamentos químicos dos hidrogênios ligados aos carbonos dos anéis pirrólicos. Observou-se no espectro de $\mathrm{RMN}$ de ${ }^{1} \mathrm{H}$ da substância analisada sinais em $\delta 7,02$; 6,71 e 6,34, concordando dados da literatura que mostram estes sinais em $\delta 7,00 ; 6,64$ e 6,33 para a tambjamina $D,{ }^{21}$ enquanto que para a tambjamina I os hidrogênios pirrólicos aparecem em $\delta 6,55$; 6,15 e $5,86 .{ }^{23}$ A identificação das substâncias $\mathbf{3}, \mathbf{4 , 6 - 8}$ foi realizada por comparação dos dados obtidos nas análises por CLAE-UVEM com informações dos bancos de dados MarinLit e Scifinder e, também, de seus espectros de RMN de ${ }^{1} \mathrm{H}$ com dados da literatura. Considerando-se a pouca massa das frações obtidas, em decorrência de limitado volume de material disponível para investigação, não foi possível isolar as substâncias puras em quantidades suficientes para realizar sua análise completa por RMN mono e bidimensional. Todavia, a análise dos espectros de massas obtidos por fragmentações de íons precursores (EM/EM) das frações isoladas de T. stegosauriformis indicou que as estruturas analisadas seguem um padrão de fragmentação que é condizente com as características estruturais das tambjaminas. No caso da tambjamina D (4), a identidade desta pôde ser inequivocamente estabelecida por comparação de seus espectro de $\mathrm{RMN}$ de ${ }^{1} \mathrm{H}$ com dados da literatura, que concordam com os dados da tambjamina D, mas não com os dados da tambjamina I (5). ${ }^{23}$ No que se refere à tambjamina $\mathrm{K}$, sua identificação foi realizada a partir das análises dos dados obtidos por CLAE-UV-EM e por EM/EM, já que não foi possível a obtenção de um espectro de RMN de ${ }^{1} \mathrm{H}$ de boa qualidade, devido à quantidade de massa disponível da fração. Subsequentemente, a investigação química do extrato do briozoário Bugula dentata levou ao isolamento das tambjaminas A (1), C (3), D (4), K (6) e J1 (9) em quantidades suficientes para a obtenção de seus dados espectroscópicos e comparação dos alcaloides isolados a partir de $T$. stegosauriformis com aqueles isolados de $B$. dentata por CLAE-UV-EM.

A análise da tambjamina C (3) por EM/EM possibilitou propor uma rota de fragmentação para esta substância (Figura 2 e Esquema 1). Utilizaram-se dados de fragmentação do íon precursor $\mathrm{m} / \mathrm{z} 246$, obtidos da fração contendo esta substância. O espectro de íons produtos de $\mathrm{m} / \mathrm{z}, 246$ contém íons com $\mathrm{m} / \mathrm{z}$ pares (oriundos da eliminação de grupos neutros não nitrogenados), sendo alguns deles rapidamente associados à eliminação de formaldeído (30 Da), indicando a presença do grupo metóxi (por exemplo, $m / z, 216$ ). A presença do grupo isobutilamina é constatada pela eliminação de isobutano $\left(\mathrm{C}_{4} \mathrm{H}_{10}, 58\right.$ Da) a partir do precursor $m / z, 246$, levando ao pico base $m / z, 188$, e pela eliminação de isobutileno $\left(\mathrm{C}_{4} \mathrm{H}_{8}, 56 \mathrm{Da}\right)$ a partir do cátion-radical $\left[\mathrm{M}+\mathrm{H}-\mathrm{CH}_{3}\right]^{\circ+}(\mathrm{m} / \mathrm{z}, 231)$ resultando no pico intenso em $\mathrm{m} / \mathrm{z}$, 175. Outros íons originados possivelmente através de rearranjos mais complexos, acompanhados de eliminação de fragmentos típicos de substâncias nitrogenadas (por exemplo, $\mathrm{HCN}, \mathrm{NH}_{3}$, pirrol), também compõem o espectro e contribuem para um fingerprinting útil para o diagnóstico estrutural desses alcaloides. Este padrão de fragmentação também foi observado nos espectros de íons obtidos dos íons precursores relativos às outras tambjaminas identificadas neste trabalho (Material Suplementar). Este é o primeiro estudo de fragmentação realizado com tambjaminas e o primeiro estudo químico realizado com Tambja stegosauriformis, espécie conhecida apenas para o Brasil e recentemente descrita. ${ }^{24}$

$\mathrm{O}$ extrato $\mathrm{MeOH}$ do briozoário Bugula dentata foi fracionado e analisado por CLAE-UV-EM. Observações de campo indicaram que este briozoário é uma presa de T. stegosauriformis e de Tambja sp. (previamente identificada erroneamente como T. eliora ${ }^{13}$ ). Diferentes tambjaminas foram isoladas de $B$. dentata da Austrália. ${ }^{25} \mathrm{O}$ processo de fracionamento e purificação do extrato de Bugula dentata levou ao isolamento das tambjaminas A (1), C (3), D (4), K (6), do 5'-bromo-4-metóxi-2,2'-bipirrol-5-carboxaldeído (8) (aldeído da tambjamina B) e de uma nova tambjamina (9), isomérica da tambjamina J (10). Todos os alcaloides bromopirrólicos isolados a partir de $B$. dentata 


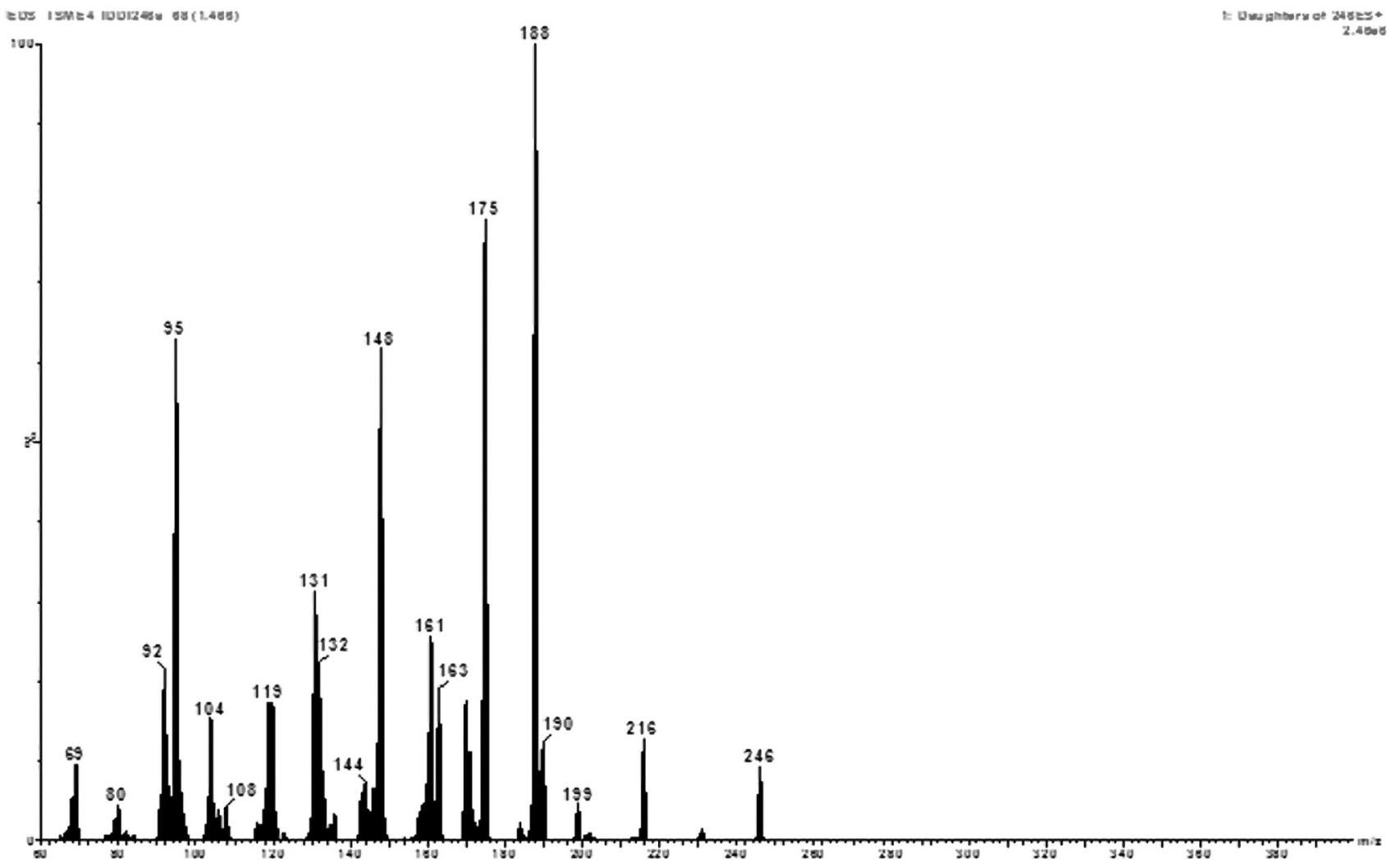

Figura 2. Espectro de massas do tipo EM/EM da tambjamina C (3)

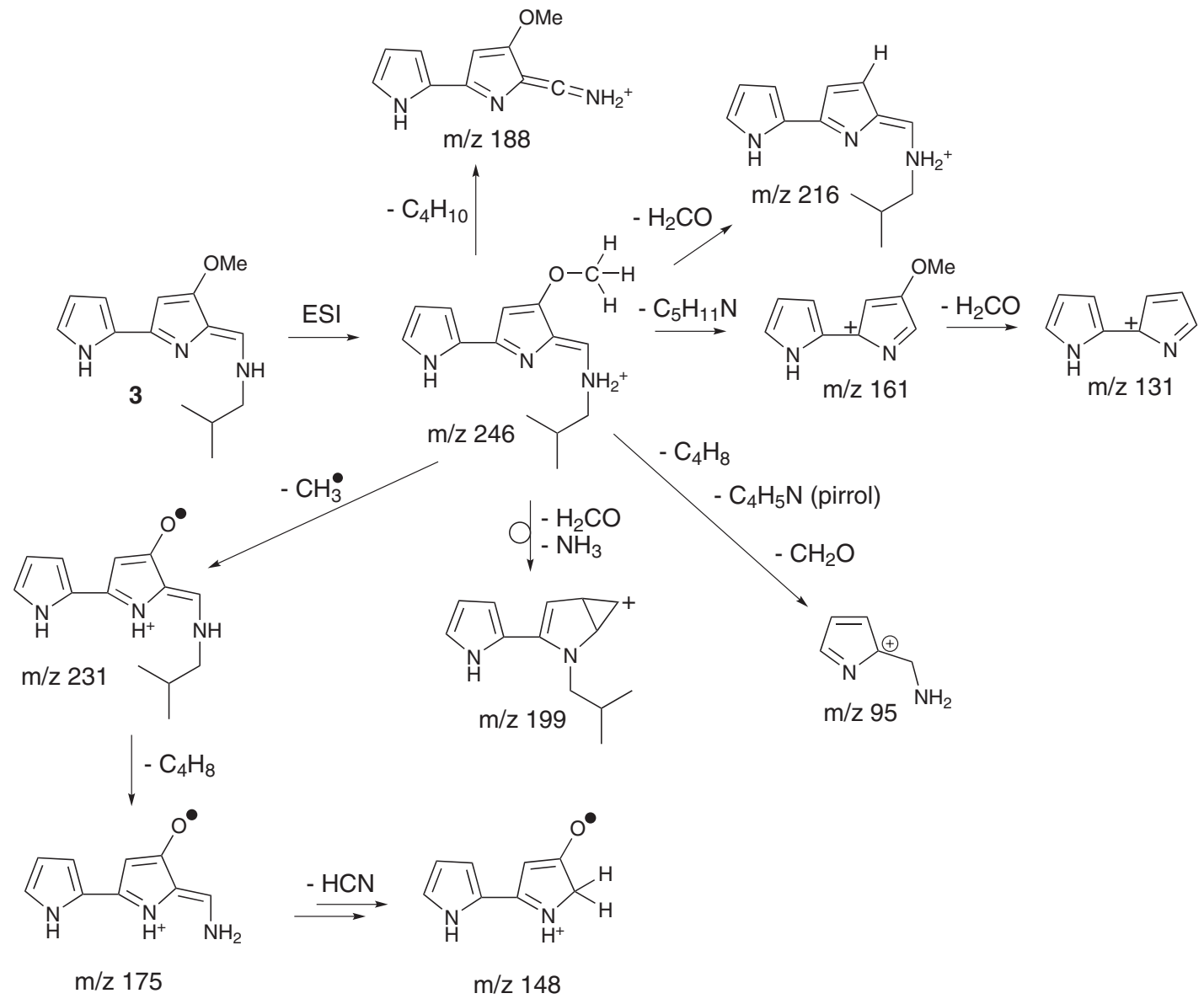

Esquema 1. Rota de fragmentação proposta para a tambjamina C (3), segundo análise de seu espectro de massas do tipo EM/EM 
foram identificados pela análise de seus dados espectroscópicos e por comparação com dados da literatura. ${ }^{21,23,25} \mathrm{O}$ alcaloide 9 apresentou, no espectro de massas obtido nas análises por LC-UV-EM (modo $\mathrm{ESI}^{+}$), dois sinais de mesma intensidade em $\mathrm{m} / z, 338$ e 340 indicando a presença de um átomo de bromo em sua estrutura. A desreplicação com informações obtidas nos bancos de dados MarinLit e SciFinder utilizando dados de UV e de massas para 9 inicialmente levaram à tambjamina $\mathbf{J}$ (10), originalmente isolado de Bugula dentata coletado na Tasmânia. ${ }^{25}$ Os dados de RMN de ${ }^{1} \mathrm{He} \mathrm{e}^{13} \mathrm{C}$ obtidos para 9 foram comparados com os dados de 10. ${ }^{25}$ Observou-se uma discrepância dos valores de deslocamento químico dos hidrogênios bis-pirrólicos de 9 com os de 10. As tambjaminas apresentam dois tipos de sistema bis-pirrólicos e a diferenciação destes é clara e evidente por RMN de ${ }^{1} \mathrm{H}$. Em $\mathrm{CDCl}_{3}$ o sistema bis-pirrólico substituído com bromo na posição 1, presente na tambjamina D (4) e no aldeído da tamjamina B (8), apresenta deslocamentos químicos em $\delta$ 6,89-7,00 (H-1), 6,33 (H-2) e 6,64-6,74 (H-6). Já o sistema bis-pirrólico substituído com bromo na posição 3, observado nas tambjaminas G (11), I (5) e J (10), apresenta deslocamentos químicos em $\delta 6,09-6,23$ (H-2), 6,40-6,63 (H-3) e 5,90-5,97 (H-6). ${ }^{13,23,25}$ Como em $\mathrm{CDCl}_{3}$ a substância 9 apresentou deslocamentos químicos em $\delta 6,66 ; 6,34$ e 7,01 para os hidrogênios bis-pirrólicos, e deslocamentos químicos idênticos aos observados para a cadeia lateral da tambjamina J (10) (dados não incluídos), tais resultados indicam que a substância isolada de $B$. dentata apresenta a estrutura 9, inédita na literatura. As atribuições observadas para os ${ }^{1} \mathrm{H}$ e ${ }^{13} \mathrm{C}$ do sistema bis-pirrólico da substância 9 (Tabela 1) puderam ser confirmadas pela análise dos espectros HMQC e HMBC (Figura 3). A estereoquímica $Z$ da ligação enamina das tambjaminas pode ser determinada em se observando efeito nOe entre o hidrogênio do carbono C-9 e o grupo metileno $\mathrm{CH}_{2}-1$ ' da cadeia ligada ao nitrogênio, mas não entre $\mathrm{CH}_{2}-1$ ' e os hidrogênios do grupo metoxila. ${ }^{26}$ Desta forma, realizamos análises por NOESY, para o estabelecimento da estereoquímica do grupo enamina na tambjamina J1 (9), utilizando a tambjamina C (3) como "controle". Para ambos os casos, observamos correlação no espectro NOESY entre o dublete do hidrogênio H-9 $(\sim \delta 7,28$, $\mathrm{CDCl}_{3}$ ) e o triplete dos hidrogênios $\mathrm{CH}_{2}-1^{\prime}(\sim \delta 3,29)$, mas não entre estes últimos e os hidrogênios da metoxila em $\delta 3,94$. Sendo assim, a estereoquímica do grupo enamina da tambjamina J1 (9) também é $Z$.

Tabela 1. Valores de deslocamento químico dos hidrogênios e carbonos do sistema bis-pirrólico da tambjamina D (4) e da tambjamina J1 (9) (DMSO- $d_{6}$, $600 \mathrm{MHz}$ )

\begin{tabular}{ccccc}
\hline \multirow{2}{*}{ Posição } & \multicolumn{3}{c}{9} & $\mathbf{4}^{13}$ \\
\cline { 2 - 5 } & ${ }^{13} \mathrm{C}$ & ${ }^{13} \mathrm{H}$ (mult., $J$ em Hz) & ${ }^{13} \mathrm{C}$ & ${ }^{1} \mathrm{H}$ (mult., $J$ em Hz) \\
\hline 1 & 123,7 & $7,20(\mathrm{t}, 3,1)$ & 124 & $7,00(\mathrm{t}, 3,0)$ \\
2 & 113,5 & $6,41(\mathrm{t}, 2,4)$ & 114,7 & $6,33(\mathrm{t}, 2,7)$ \\
6 & 93,7 & $6,56(\mathrm{~d}, 2,2)$ & 92,8 & $6,61(\mathrm{~d}, 2,4)$ \\
\hline
\end{tabular}

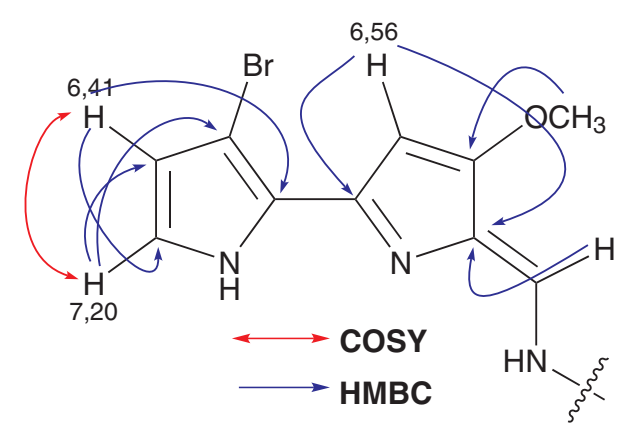

Figura 3. Correlações observadas nos espectros de tipo COSY e HMBC da tambjamina $J 1$ (9)
Desta forma, o estudo químico do nudibrânquio T. stegosauriformis e do briozoário predado por este molusco, Bugula dentata, levou ao isolamento de uma série de tambjaminas, dentre as quais a tambjamina J1 (9), inédita na literatura.

\section{Investigação química do extrato do nudibrânquio Hypselodoris lajensis}

O fracionamento do extrato EtOH do nudibrânquio Hypselodoris lajensis resultou no isolamento da lactona da furodisinina (12) (Figura 4), uma substância originalmente isolada da esponja Dysidea etheria. ${ }^{27}$ Este sesquiterpeno teve sua estrutura elucidada após a análise dos dados espectroscópicos ( $\mathrm{RMN}{ }^{1} \mathrm{H},{ }^{13} \mathrm{C}, \mathrm{COSY}$, HSQC e HMBC) e a comparação destes com dados da literatura. ${ }^{26}$ Recentemente, a lactona da furodisinina foi isolada a partir do extrato hexânico da esponja marinha Dysidea sp. ${ }^{20}$ (provavelmente D. etheria). Tal resultado indica que o nudibrânquio possivelmente captura a substância 12 da esponja Dysidea sp., que constitui sua presa. Este é o primeiro trabalho que mostra o isolamento da lactona da furodisinina a partir de um nudibrânquio.<smiles>CC1=C[C@H]2C[C@]3(O)OC(=O)C=C3C(C)(C)[C@@H]2CC1</smiles>

12<smiles>CN(C)Cc1c(Br)n(C)c2cc(Br)c(Br)cc12</smiles>

13
Figura 4. Estruturas químicas da lactona da furodisinina (12) e da 2,5,6-tribromo-N-metilgramina (13)

\section{Investigação química dos extratos do nudibrânquio Okenia zoobotryon e do briozoário Zoobotryon verticillatum}

O fracionamento do extrato metanólico do nudibrânquio $O$. zoobotryon levou ao isolamento da 2,5,6-tribromo- $N$-metilgramina (13) ${ }^{19}$ (Figura 4). Esta foi identificada pela análise dos seus espectros de RMN de ${ }^{1} \mathrm{H}$ e massas, e por comparação com dados da literatura.

Como foi observado que $O$. zoobotryon vive associado ao briozoário Zoobotryon verticillatum, espécimens do briozoário também foram coletados e extraídos com EtOH e MeOH. O fracionamento cromatográfico do extrato $\mathrm{MeOH}$ do briozoário forneceu a mesma substância 2,5,6-tribromo- $N$-metilgramina encontrada nos espécimens de $O$. zoobotryon. Frações contendo a mesma substância isolada do molusco e do briozoário foram analisadas por CLAE-UV-EM, comparando-se seus espectros de massas, o tempo de retenção e, também, seus espectros de RMN de ${ }^{1} \mathrm{H}$.

A substância 13 já havia sido anteriormente isolada do briozoário Z. verticillatum. ${ }^{19}$ Embora estudos já tivessem relatado a interação entre $O$. zoobotryon e $Z$. verticillatum, e que o nudibrânquio se alimenta deste briozoário, ${ }^{18}$ este é o primeiro estudo que apresenta o isolamento do derivado indólico tribromado $\mathbf{1 3}$ a partir do nudibrânquio $O$. zoobotryon e de sua presa, indicando que este molusco realmente assimila e armazena esta substância a partir de Z.verticillatum.

\section{CONCLUSÃO}

O estudo dos extratos de três espécies de nudibrânquios, $T$. stegosauriformis, H. lajensis e O. zoobotryon, levou ao isolamento de metabólitos secundários também encontrados em suas presas: o briozoário Bugula dentata, a esponja Dysidea sp. e o briozoário Z. verticillatum, respectivamente. A composição de tambjaminas 
observada em T. stegosauriformis (predador) e B. dentata (presa) apresenta variações, sendo que o briozoário (presa) apresenta uma maior variedade de alcaloides do que o molusco (predador). Dentre os alcaloides isolados de B. dentata, a tambjamina J1 (9) é inédita na literatura. Já os estudos dos nudibrânquios $H$. lajensis e $O$. zoobotryon indicaram que a composição química de seus extratos é constituída pela mesma substância principal encontrada em suas presas. Os resultados sugerem que as mesmas substâncias majoritárias isoladas, tanto das presas como dos predadores, podem exercer funções similares nos moluscos e nos invertebrados sésseis.

Esta é a primeira investigação com foco em nudibrânquios da costa brasileira. Além disso, é a primeira investigação química destas espécies de nudibrânquios e das espécies de briozoários coletadas no Brasil. Os resultados indicam a importância na descoberta de metabólitos secundários que tomam parte em relações entre presa e predador, envolvendo nudibrânquios e outros invertebrados marinhos pouco conhecidos no Brasil.

\section{MATERIAL SUPLEMENTAR}

Está disponível em http://quimicanova.sbq.org.br, na forma de arquivo pdf, com acesso livre.

\section{PARTE EXPERIMENTAL}

\section{Generalidades}

Os espectros de RMN foram obtidos a $25{ }^{\circ} \mathrm{C}$, utilizando-se TMS como padrão interno, em um aparelho Bruker ARX 9.4 Tesla operando em $400.35 \mathrm{MHz}\left({ }^{1} \mathrm{H}\right)$ e $100.10 \mathrm{MHz}\left({ }^{13} \mathrm{C}\right)$. As análises por CLAE-UV-EM foram realizados em um equipamento Waters Alliance 2695 acoplado on-line a um detector de arranjo de fotodiodos (PDA) Waters 2996 e um detector de espectrometria de massas Micromass ZQ2000, utilizando ionização por eletrospray, no qual foram obtidos os espectros de massas de baixa resolução. Os espectros de massas EM/EM foram obtidos em um aparelho CLAE-UVESI-EM/EM, com resolução cromatográfica em um sistema Alliance 2695 (Waters), detecção por arranjo de diodos PDA 2996 (Waters) e acoplado a um espectrômetro de massas do tipo triplo quadrupolo, modelo Micromass QuattroLC (Manchester, U.K), equipado com uma fonte de íons API Z-spray e uma sonda para ionização electrospray em alto fluxo. A ionização foi feita no modo positivo. As resoluções cromatográficas foram realizadas em uma coluna Waters Spherisorb ODS2 $(125 \mathrm{~mm} \times 4.0 \mathrm{~mm}$ d.i., $5 \mu \mathrm{m})$; fluxo: $0,8 \mathrm{~mL}$ $\min ^{-1} ; \lambda_{\text {max }}$ detecção, $215-600 \mathrm{~nm}$. O gradiente de eluição utilizado foi $\left(\mathrm{A}=\mathrm{H}_{2} \mathrm{O}, \mathrm{B}=\mathrm{MeCN}, \mathrm{C}=\mathrm{MeOH}\right): 60 \% \mathrm{~A}+15 \% \mathrm{~B}+25 \% \mathrm{C}$ até $40 \% \mathrm{~A}+15 \% \mathrm{~B}+45 \% \mathrm{C}$ em 8 min, então $30 \% \mathrm{~A}+15 \% \mathrm{~B}+$ $55 \% \mathrm{C}$ em $15 \mathrm{~min}$. No final, a coluna foi lavada com $100 \% \mathrm{C}$ por 2 min, e então recondicionada com $70 \% \mathrm{~A}+10 \% \mathrm{~B}+20 \% \mathrm{C}$ por

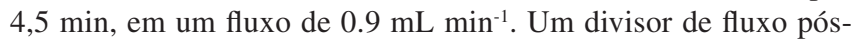
-coluna foi utilizado para enviar apenas $0,25 \mathrm{~mL} \mathrm{~min}^{-1}$ do efluente da coluna para a fonte de ionização. Nitrogênio foi utilizado como gás nebulizador $(34 \mathrm{~L} / \mathrm{h})$ e de dessolvatação $(834 \mathrm{~L} / \mathrm{h})$. O capilar da sonda de ESI foi mantido em uma voltagem de $3,57 \mathrm{kV}$, com os cones de amostragem e de extração em 46 e $4 \mathrm{~V}$, respectivamente. Argônio foi utilizado nos experimentos de fragmentação e os íons precursores foram acelerados usando-se uma rampa de energia de colisão de 5-35 eV. Foram utilizados solventes de grau analítico (P.A.) para a extração e cromatografia em coluna de baixa pressão flash. Foram utilizados solventes de grau cromatográfico (CLAE) e água MilliQ em separações semipreparativas por cromatografia líquida, utilizando-se um equipamento Waters de bomba quaternária 600 e detector de duplo feixe UV 2487.

\section{Estudo químico do nudibrânquio Tambja stegosauriformis}

Espécimes do nudibrânquio Tambja stegosauriformis (3 indivíduos, com 5 a $7 \mathrm{~cm}$ de comprimento) foram coletados na Ilha do Papagaio, em Cabo Frio, RJ, Brasil e preservados em EtOH. Um exemplar de referência foi depositado no Museu de Zoologia da Universidade de São Paulo (MZSP 97621). O processo de extração foi realizado da seguinte forma: após separação do EtOH de preservação, os animais foram transferidos para $40 \mathrm{~mL}$ de EtOH. Os animais em EtOH foram sonicados em banho de ultrassom por 2 min e deixados em repouso por mais $30 \mathrm{~min}$. Removeu-se o EtOH e adicionaram-se mais $40 \mathrm{~mL}$ do mesmo solvente, repetindo-se esta operação mais uma vez. Após a extração, todo o EtOH de preservação e de extração, foi evaporado resultando no extrato etanólico do nudibrânquio. Os animais foram re-extraídos com $\mathrm{MeOH}$ (3 x $40 \mathrm{~mL}$ ). Os extratos metanólico e etanólico foram reunidos e concentrados até um volume de $300 \mathrm{~mL}$. A suspensão alcoólica assim obtida foi particionada com hexano. Após evaporação das frações polar e apolar obtiveram-se os extratos brutos metanólico (Tsme, 361,3 mg) e hexânico (Tshx, 143,0 $\mathrm{mg}$ ), os quais foram analisados por CLAE-UV-EM.

O extrato metanólico (Tsme, 361,3 mg) foi separado por CLAE [coluna Waters Deltapak $\mathrm{C}_{18}$, de $300 \times 7,8 \mathrm{~mm} ; 15 \mu \mathrm{m}$; eluente: $\mathrm{MeOH} / \mathrm{H}_{2} \mathrm{O} 67: 33$ (0,05\% TFA) ; fluxo: $1,2 \mathrm{~mL} / \mathrm{min}$; detecção: UV $\lambda_{\max } 254 \mathrm{~nm}$ ], obtendo-se nove novas frações: Tsme-1 (102,9 mg), Tsme-2 (14,6 mg), Tsme-3 (1,5 mg), Tsme-4 (1,6 mg), Tsme-5 (1,2 $\mathrm{mg})$, Tsme-6 (0,8 mg), Tsme-7 (2,3 mg), Tsme-8 (1,5 mg) e Tsmelav (7,2 mg). Todas as frações foram analisadas por CLAE-UV-EM [coluna: Waters XTerra EM C $\mathrm{C}_{18}$, de 2,1 x $50 \mathrm{~mm}$; 3,5 $\mu \mathrm{m}$; eluente: gradiente de $\mathrm{MeOH} / \mathrm{MeCN}$ 1:1 em $\mathrm{H}_{2} \mathrm{O}$ (0,1\% TFA); fluxo: 0,5 mL/ min; UV: espectro obtido entre 200 e $600 \mathrm{~nm}$; EM: $\mathrm{ESI}^{+}$, voltagem do cone $=20 \mathrm{~V}]$. A fração Tsme- 2 foi submetida à separação posterior por CLAE [coluna: Inertsil Phenyl (GL Sciences, Inc), de 250 x 4,6 mm; $5 \mu \mathrm{m}$; eluente: gradiente de $\mathrm{MeOH} / \mathrm{MeCN}$ 1:1 em $\mathrm{H}_{2} \mathrm{O}(0,1 \%$ TFA); fluxo: 1,0 mL/min; detecção: UV $\lambda_{\text {max }} 254 \mathrm{~nm}$ ], obtendo-se quatro novas frações: Tsme-2b1 (2,7 mg), Tsme-2b2 (2,5 mg), Tsme$2 \mathrm{~b} 3(0,8 \mathrm{mg})$ e Tsme-2b4 (0,7 mg), as quais foram analisadas por CLAE-UV-EM nas mesmas condições citadas acima. As substâncias identificadas foram observadas nas seguintes frações: Tsme-2b1 (aldeído da tambjamina A (7), $\mathrm{t}_{\mathrm{R}}=5,8 \mathrm{~min}$ ), Tsme-4 (tambjamina $\mathrm{C}$ (3), $\mathrm{t}_{\mathrm{R}}=2,02 \mathrm{~min}$ ), Tsme-6 (tambjamina $\left.\mathrm{K}(\mathbf{6}), \mathrm{t}_{\mathrm{R}}=1,39 \mathrm{~min}\right)$, Tsme-7 (tambjamina $\mathrm{D}(\mathbf{4}), \mathrm{t}_{\mathrm{R}}=5,12 \mathrm{~min}$ ) e Tsme-8 (aldeído da tambjamina $\left.\mathrm{B}(\mathbf{8}), \mathrm{t}_{\mathrm{R}}=5,2 \mathrm{~min}\right)$.

\section{Tambjamina $C(\mathbf{3})$}

Óleo esverdeado. EM-ESI ${ }^{+}: m / z$ 246; UV: $\lambda_{\max } 258$ e $398 \mathrm{~nm}$; RMN de ${ }^{1} \mathrm{H}\left(\mathrm{CDCl}_{3}, 400 \mathrm{MHz}\right): 7,27$ (d, 19,4 Hz, 1H, H-9), 7,09 (m, $1 \mathrm{H}, \mathrm{H}-1), 6,75$ (m, 1H, H-3), 6,28 (m, 1H, H-2), 5,98 (s, 1H, H-6), 3,93 (s, 3H, OMe), 3,28 (t, 6,4 Hz, 2H, $\mathrm{CH}_{2}-1^{\prime}$ ), 1,99 (m, 1H, H-2'), 1,00 (d, 6,7 Hz, 6H, $\mathrm{CH}_{3}-3$ ' e $\mathrm{CH}_{3}-4$ ').

\section{Tambjamina $D$ (4)}

Óleo esverdeado. EM-ESI+: $m / z 324$ e 326; UV: $\lambda_{\max } 256$ e 399 nm; RMN de ${ }^{1} \mathrm{H}\left(\mathrm{CDCl}_{3}, 400 \mathrm{MHz}\right):$ 7,40 (d, $\left.15 \mathrm{~Hz}, 1 \mathrm{H}, \mathrm{H}-9\right), 7,02$ (m, 1H, H-1), 6,71 (d, 2,3 Hz, 1H, H-6), 6,34 (m, 1H, H-2), 3,97 (s, $3 \mathrm{H}, \mathrm{OMe}$ ), 3,30 (m, 2H, $\mathrm{CH}_{2}-^{\prime}$ '), 2,01 (m, 1H, H-2'), 1,01 (d, 6,7 $\mathrm{Hz}, 6 \mathrm{H}, \mathrm{CH}_{3}-3$ ' e $\mathrm{CH}_{3}-4$ ').

\section{Tambjamina $K(\boldsymbol{6})$}

Óleo esverdeado. EM-ESI': $m / z, 260 ; \mathrm{UV}: \lambda_{\max } 258,323$ e $403 \mathrm{~nm}$.

\section{4-metóxi-2,2'-bipirrol-5-carboxaldeído (7)}

Óleo esverdeado. EM-ESI ${ }^{+}: m / z, 191$; UV: $\lambda_{\max } 251$ e $364 \mathrm{~nm}$; RMN de ${ }^{1} \mathrm{H}$ (DMSO- $\left.d_{6}, 600 \mathrm{MHz}\right): 11,4$ (s, NH), 11,23 (s, NH), 9,28 
(s, 1H, H-9), 6,89 (d, 1,4 Hz, 1H, H-1), 6,74 (m, 1H, H-3), 6,26 (d, 2, $7 \mathrm{~Hz}, 1 \mathrm{H}, \mathrm{H}-6), 6,10$ (dd, 2,5 e 5,8 Hz, 1H, H-2), 3,82 (s, 3H, $\mathrm{CH}_{3}$ ).

\section{5'-bromo-4-metóxi-2,2'-bipirrol-5-carboxaldeído (8)}

Óleo esverdeado. EM-ESI+: $m / z, 269$ e $271 ; \mathrm{UV}: \lambda_{\max } 247$ e 359 $\mathrm{nm}$; RMN de ${ }^{1} \mathrm{H}$ (DMSO- $\left.d_{6}, 400 \mathrm{MHz}\right): 11,50$ (s, NH), 11,28 (s, NH), 9,39 (s, 1H, H-9), 7,01 (t, 3Hz, 1H, H-1), 6,53 (d, 2,3 Hz, 1H, H-6), 6,28 (t, 2,7 Hz, 1H, H-2), 3,87 (s, 3H, $\left.\mathrm{CH}_{3}\right)$.

\section{Estudo químico do briozoário Bugula dentata}

Colônias do briozoário ( $32 \mathrm{~g}$, peso seco) foram coletadas em Cabo Frio-RJ, congeladas e liofilizadas. Um exemplar de referência foi mantido na coleção de referência de coletas do IQSC-USP (AC11BRY-01). A massa dos espécimes foi triturada em liquidificador com $\mathrm{MeOH}$. O extrato foi filtrado através de celite sobre papel de filtro. Após a filtração, a massa triturada foi extraída mais 4 vezes com $\mathrm{MeOH}$. Todo o $\mathrm{MeOH}$ filtrado (2 L) foi concentrado em evaporador rotativo até um volume de $300 \mathrm{~mL}$. Adicionaram-se $30 \mathrm{~mL}$ de $\mathrm{H}_{2} \mathrm{O}$ e realizou-se uma partição com hexano ( 4 x $300 \mathrm{~mL}$ ). O extrato hexânico foi evaporado, seco e guardado.

$\mathrm{O}$ extrato $\mathrm{MeOH}$ obtido (2,6 g) foi submetido a uma cromatografia em coluna pré-empacotada de sílica gel derivatizada com grupos $\mathrm{C}_{18}$. Utilizou-se um gradiente de $\mathrm{MeOH}$ e $\mathrm{MeCN}$ em $\mathrm{H}_{2} \mathrm{O}\left(\mathrm{H}_{2} \mathrm{O}\right.$ $100 \%, \mathrm{H}_{2} \mathrm{O} / \mathrm{MeOH}$ 8:2, 7:3, 6:4, 1:1, 4:6, 3:7, 2:8, MeOH 100\% e $\mathrm{MeCN} 100 \%$ ) como eluente. As frações coletadas foram analisadas por CCD utilizando-se os reveladores ácido fosfomolíbdico e ninidrina, e reunidas de acordo com seu padrão cromatográfico. Foram obtidas dez frações: CF11BRI-2A (1,9 g), CF11BRI-2B (86,5 mg), CF11BRI-2C (36,5 mg), CF11BRI-2D (40,1 mg), CF11BRI-2E (54,2 $\mathrm{mg}), \mathrm{CF} 11 \mathrm{BRI}-2 \mathrm{~F}$ (50,3 mg), CF11BRI-2G (27,0 mg), CF11BRI-2H (34,0 mg), CF11BRI-2I (78,2 mg) e CF11BRI-lav (126,7 mg). Todas estas frações foram analisadas por CLAE-UV-EM, utilizando-se uma coluna Inertsil ODS-SP, $5 \mu \mathrm{m}, 4,6$ x 250 mm, GL Sciences Inc., com um gradiente de $\mathrm{MeOH} / \mathrm{MeCN}$ 1:1 em $\mathrm{H}_{2} \mathrm{O}(0,1 \%$ TFA $)$ como eluente [fluxo: $1,0 \mathrm{~mL} / \mathrm{min}$; detecção em $\lambda_{\max }$ entre 200 e $600 \mathrm{~nm}$ e por EM $\left(\right.$ modo $\mathrm{ESI}^{+}$, voltagem do cone $\left.=20 \mathrm{~V}\right]$. Este mesmo procedimento foi utilizado em todas as análises por CLAE-UV-EM de frações do extrato $\mathrm{MeOH}$ de Bugula dentata.

A fração CF11BRI-2G (27 mg) foi purificada por HPLC em coluna de fase reversa $\mathrm{C}_{18}$, utilizando-se um gradiente de $\mathrm{MeOH} / \mathrm{MeCN}$ 1:1 em $\mathrm{H}_{2} \mathrm{O}$ (início com $40 \%$ de eluente orgânico; $\mathrm{H}_{2} \mathrm{O}$ com $0,05 \%$ de TFA) em uma coluna semipreparativa de sílica gel derivatizada por grupos $\mathrm{C}_{18}$ (CSC-Inertsil 150A/ODS2, $5 \mu \mathrm{m}, 250$ x 9,4 mm). Foram obtidas nove frações: CF11BRI-2G1 (2,6 mg), -2G2 (2,5 mg), -2G3 (1,3 mg), -2G4 (2,5 mg), -2G5 (2,4 mg), -2G6 (2,0 mg), -2G7 (2,4 mg), -2G8 (1,5 mg) e -2G9 (6,0 mg). As análises por CLAE-UV-EM indicaram que a fração CF11BRI-2G5 era constituída pelo aldeído da tambjamina B (8).

A fração CF11BRI-2H (34,6 mg) foi separada nas mesmas condições, fornecendo nove novas frações: CF11BRI-2H1 (3,2 mg), -2H2 (2,9 mg), -2H3 (1,0 mg), -2H4 (1,9 mg), -2H5 (4,0 mg), -2H6 (1,2 mg), -2H7 (2,0 mg), -2H8 (1,9 mg), -2H9 (2,5 mg) e -2H10 (9,8 $\mathrm{mg})$. As tambjaminas A (1) e C (3) foram identificadas nas frações CF11BRI-2H2 e -2H5, respectivamente, a partir dos dados obtidos por CLAE-UV-EM e comparação de seus espectros de RMN de ${ }^{1} \mathrm{H}$ $\mathrm{e}^{13} \mathrm{C}$ com dados da literatura.

A fração CF11BRI-2I foi separada por CLAE, nas mesmas condições citadas utilizadas para a separação da fração CF11BRI-2G, fornecendo as frações CF11BRI-2I1 (13,1 mg), -2I2 (8,4 mg), -2I3 (7,4 mg), -2I4 (8,3 mg), -2I5 (4,0 mg), -2I6 (10,0 mg), -2I7 (1,7 mg), e -2I8 (12,8 mg). A tambjamina D (4) foi identificada na fração -2I6 após comparação dos seus espectros de $\mathrm{RMN}$ de ${ }^{1} \mathrm{H},{ }^{13} \mathrm{C}$ e massas de baixa resolução (modo $\mathrm{ESI}^{+}$) com dados da literatura. Na fração CF11BRI-2I7 foi identificada a tambjamina J1 (9) a partir da análise dos dados obtidos por CLAE-UV-EM e espectros de RMN mono e bidimensionais. Após análise por CLAE-UV-EM, a fração CF11BRI2 I5 foi purificada por HPLC em fase reversa (coluna Inertsil ODS-SP, $5 \mu \mathrm{m}, 4,6$ x $250 \mathrm{~mm}$, GL Sciences Inc.) utilizando-se MeOH/MeCN/ $\mathrm{H}_{2} \mathrm{O}$ 3:2:5 como eluente em modo isocrático. Foram obtidas seis frações: CF11BRI-2I5a (0,7 mg), CF11BRI-2I5b (0,4 mg), CF11BRI2I5c (1,2 mg), CF11BRI-2I5d (0,4 mg), CF11BRI-2I5e (0,7 mg) e CF11BRI-2I5f (0,4 mg). A tambjamina $\mathrm{K}(\mathbf{6})$ foi identificada na fração CF11BRI-2I5c.

\section{Tambjamina A (1)}

Óleo esverdeado. EM-ESI : $\mathrm{m} / z$ 190; UV: $\lambda_{\max } 216,250$ e 392 $\mathrm{nm} ; \mathrm{RMN}$ de ${ }^{1} \mathrm{H}\left(\mathrm{CDCl}_{3}, 400 \mathrm{MHz}\right): 7,52(\mathrm{~m}, 1 \mathrm{H}, \mathrm{H}-9), 7,13(\mathrm{~m}$, 1H, H-1), 6,82 (m, 1H, H-2), 6,32 (m, 1H, H-3), 5,98 (m, 1H, H-6), $3,96(\mathrm{~s}, 3 \mathrm{H}, \mathrm{OMe})$.

\section{Tambjamina $C(\mathbf{3})$}

Óleo esverdeado. EM-ESI': $m / z$, 246; UV: $\lambda_{\max } 217,258$ e 402 nm; RMN de ${ }^{1} \mathrm{H}\left(\mathrm{CDCl}_{3}, 400 \mathrm{MHz}\right): 7,28$ (d, $\left.15 \mathrm{~Hz}, 1 \mathrm{H}, \mathrm{H}-9\right), 7,10$ (m, 1H, H-1), 6,76 (m, 1H, H-3), 6,29 (m, 1H, H-2), 5,98 (m, 1H, H-6), 3,94 (s, 3H, OMe), 3,29 (t, 6,4 Hz, 2H, $\mathrm{CH}_{2}-1$ '), 2,00 (m, 1H, H-2'), 1,01 (d, 6,7 Hz, 6H, $\mathrm{CH}_{3}-3$ ' e $\mathrm{CH}_{3}-4^{\prime}$ ).

\section{Tambjamina $D(4)$}

Óleo esverdeado. EM-ESI': $m / z, 324$ e 326; UV: $\lambda_{\max } 256$ e 397 $\mathrm{nm} ; \mathrm{RMN}$ de ${ }^{1} \mathrm{H}\left(\mathrm{CDCl}_{3}, 400 \mathrm{MHz}\right): 7,40$ (d, $\left.15 \mathrm{~Hz}, 1 \mathrm{H}, \mathrm{H}-9\right), 7,03$ (m, 1H, H-1), 6,71 (d, 2,3 Hz, 1H, H-6), 6,35 (m, 1H, H-2), 3,97 (s, $3 \mathrm{H}, \mathrm{OMe}$ ), 3,31 (m, 2H, $\mathrm{CH}_{2}-1^{\prime}$ ), 2,01 (m, 1H, H-2'), 1,01 (d, 6,7 $\mathrm{Hz}, 6 \mathrm{H}, \mathrm{CH}_{3}-3^{\prime}$ e $\mathrm{CH}_{3}-4$ ').

\section{Tambjamina $K(\boldsymbol{6})$}

Óleo esverdeado. EM-ESI ${ }^{+}: m / z, 260 ; \mathrm{UV}: \lambda_{\max } 258,323$ e $403 \mathrm{~nm}$; RMN de ${ }^{1} \mathrm{H}\left(\mathrm{CDCl}_{3}, 400 \mathrm{MHz}\right):$ 7,30 (d, 14,9 Hz, 1H, H-9), 7,09 (m, 1H, H-1), 6,75 (m, 1H, H-3), 6,29 (m, 1H, H-2), 5,98 (s, 1H, H-6), 3,94 (s, 3H, OMe), 3,49 (m, 2H, H-1'), 1,77 (m, 1H, H-3'), 1,63 (m, 2H, H-2'), 1,00 (d, 6,8 Hz, 3H, H-4') e 0,95 (d, 6,8 Hz, 3H, H-5').

\section{5'-bromo-4-metóxi-2,2'-bipirrol-5-carboxaldeído $(8)$}

Óleo esverdeado. EM-ESI+: $m / z$, 269 e 271; UV: $\lambda_{\max } 220$ e 357 $\mathrm{nm} ; \mathrm{RMN}^{\mathrm{de}}{ }^{1} \mathrm{H}$ (DMSO- $\left.d_{6}, 400 \mathrm{MHz}\right): 11,50$ (s, NH), 11,28 (s, NH), 9,39 (s, 1H, H-9), 7,01 (t, 3Hz, 1H, H-1), 6,53 (d, 2,3 Hz, 1H, H-6), $6,28(\mathrm{t}, 2,7 \mathrm{~Hz}, 1 \mathrm{H}, \mathrm{H}-2), 3,87$ (s, 3H, $\left.\mathrm{CH}_{3}\right)$.

\section{Tambjamina J1 (9)}

Óleo esverdeado. EM-ESI ${ }^{+}: m / z 338$ e 340; UV: $\lambda_{\max } 219$ e 398 $\mathrm{nm}$; RMN de ${ }^{1} \mathrm{H}$ (DMSO- $\left.d_{6}, 600 \mathrm{MHz}\right): 8,16$ (d, $\left.15 \mathrm{~Hz}, 1 \mathrm{H}, \mathrm{H}-9\right)$, 7,20 (t, 3,1 Hz, 1H, H-1), 6,56 (d, 2,2 Hz, 1H, H-6), 6,41 (t, 2,4 Hz, 1H, H-2), 3,97 (s, 3H, OMe), 3, 17 (m, 2H, H-1'), 1,24 (m, 3H, H-5'), 0,92 (m, 3H, H-4')

RMN de ${ }^{13} \mathrm{C}$ (DMSO- $\left.d_{6}, 150 \mathrm{MHz}\right): 162,6$ (C-7), 145,1 (C-9), 138,0 (C-5), 123,7 (C-1), 119,6 (C-4), 113,5 (C-2), 109,5 (C-8), 98,5 (C-3), 93,7 (C-6), 58,6 (OMe), 48,5 (C-1') , 16,4 (C-5'), 10,9 (C-4').

\section{Estudo químico do nudibrânquio Hypselodoris lajensis}

Espécimes do nudibrânquio $H$. lajensis (3 indivíduos, com 3 a $5 \mathrm{~cm}$ de comprimento) foram coletados em Cabo Frio, RJ, Brasil e foram preservados em EtOH. A identificação do material foi feita por V. Padula, e exemplares de referência foram depositados no Museu de Zoologia da Universidade de São Paulo (MZSP 97467). O processo de extração foi realizado da seguinte forma: após separação do EtOH 
de preservação, os animais foram transferidos para $40 \mathrm{~mL}$ de EtOH. Os animais em EtOH foram sonicados em banho de ultrassom por 2 $\mathrm{min}$, deixando-se em repouso por mais $30 \mathrm{~min}$. Removeu-se o EtOH e adicionaram-se mais $40 \mathrm{~mL}$ do mesmo solvente, repetindo-se esta operação mais uma vez. Após a extração, todo o EtOH, de preservação e de extração foi reunido e evaporado, resultando no extrato etanólico (Hyet, 278,5 mg) do nudibrânquio. Os animais foram re-extraídos com MeOH ( 3 x $40 \mathrm{~mL})$ e $\mathrm{CH}_{2} \mathrm{Cl}_{2}$ ( 3 x $\left.40 \mathrm{~mL}\right)$. O extrato etanólico foi reunido com o extrato metanólico e este extrato alcoólico foi evaporado, obtendo-se o extrato alcoólico dos animais (HyMe, 12.8 $\mathrm{mg}$ ). $\mathrm{O}$ extrato $\mathrm{CH}_{2} \mathrm{Cl}_{2}$ também foi evaporado, obtendo-se apenas $1,1 \mathrm{mg}$ deste último.

O extrato alcoólico (Hyet, 278,5 mg) do animal foi submetido a uma separação por cromatografia em coluna pré-empacotada contendo sílica gel derivatizada com grupos $\mathrm{C}_{18}$ como fase estacionária (10 g), utilizando-se um gradiente de $\mathrm{MeOH}$ e $\mathrm{H}_{2} \mathrm{O}$ como eluente $\left(\mathrm{H}_{2} \mathrm{O}\right.$ $100 \%, \mathrm{H}_{2} \mathrm{O} / \mathrm{MeOH}$ 8:2, 6:4, 4:6 e MeOH 100\%). Após análises por $\mathrm{CCD}\left(\mathrm{CH}_{2} \mathrm{Cl}_{2} / \mathrm{MeOH}\right.$ 9:1 e 7:3 como eluentes e ácido fosfomolíbdico, ninidrina e Dragendorff como reveladores) das diversas frações obtidas, estas foram reunidas em cinco frações: Hyet-1 (253,1 mg), Hyet-2 (10,1 mg), Hyet-3 (4,6 mg), Hyet-4 (5,8 mg) e Hyet-5 (18,9 mg). Estas frações foram analisadas por CLAE-UV-EM [coluna: Waters XTerra $\mathrm{EM} \mathrm{C}_{18}$, de 2,1 x $50 \mathrm{~mm}$; 3,5 $\mu$ m; eluente: gradiente de $\mathrm{MeOH} / \mathrm{MeCN}$ 1:1 em $\mathrm{H}_{2} \mathrm{O}$ (0,1\% TFA); fluxo: 0,5 mL/min; UV: espectro obtido entre 200 e 400 nm; EM: ESI ${ }^{+}$, voltagem do cone $=25$ V].

A fração Hyet-4 foi submetida a uma purificação por CLAE [coluna: Synergi $4 \mu$ Fusion-RP $80 \mathrm{C}_{18}$ (Phenomenex), de 250 x 4,6 $\mathrm{mm} ; 4 \mu \mathrm{m}$; eluente: $\mathrm{MeOH} / \mathrm{H}_{2} \mathrm{O}$ 6:4 (0,1\% TFA) ; fluxo: $0,9 \mathrm{~mL} / \mathrm{min}$; detecção: UV $\lambda_{\max } 254 \mathrm{~nm}$ ]. A fração obtida Hyet-4c $(1,4 \mathrm{mg})$ foi identificada como sendo a lactona da furodisinina (12).

\section{Lactona da furodisinina (12)}

$[\alpha]_{\mathrm{D}}^{20}=+100(\mathrm{c}=1,0 \mathrm{mg} / \mathrm{mL}, \mathrm{MeOH}) ; \mathrm{EM}-\mathrm{ESI}^{+}: \mathrm{m} / \mathrm{z}$ 249; ESIEM: $m / z, 247$; UV: $\lambda_{\text {max }} 226 \mathrm{~nm}$; RMN de ${ }^{1} \mathrm{H}\left(\mathrm{DMSO}-d_{6}, 400\right.$ MHz): 5,79 (s, H-2), 5,35 (d, 4,7 Hz, H-7), 2,68 (d, 8,5 Hz, H-6), 2, 18 (dd, 13,2 e 3,5, H-5a), 1,91 (m, 2H, $\left.\mathrm{CH}_{2}-9\right), 1,61$ (m, H-11), 1,59 (m, H-10a), 1,58 (s, 3H, $\mathrm{CH}_{3}-15$ ), 1,36, (d, 13,0 Hz, H-5b), 1,31 (s, 3H, $\left.\mathrm{CH}_{3}-14\right), 1,16$ (s, 3H, $\left.\mathrm{CH}_{3}-13\right), 1,10$ (m, H-10b).

\section{Estudo químico do nudibrânquio Okenia zoobotryon}

Espécimes do nudibrânquio $O$. zoobotryon (50 indivíduos, com aproximadamente $7 \mathrm{~mm}$ de comprimento cada) foram coletados em Cabo Frio, RJ, Brasil e preservados em EtOH. A identificação do material foi feita por V. Padula e exemplares de referência foram depositados no Museu de Zoologia da Universidade de São Paulo (MZSP 97093). O processo de extração para este animal foi realizado de maneira análoga ao procedimento utilizado na extração do $H$. lajensis, resultando nos extratos etanólico (OkEt, $230 \mathrm{mg}$ ), metanólico (OkMe, 12,8 mg) e diclorometano (OkDM, 1,1 mg), os quais foram analisados por CLAE-UV-EM.

O extrato OkEt foi submetido a uma separação por CLAE [coluna: CSC-Inertsil 150A/ODS-2 $\mathrm{C}_{18}$, de 250 x 9,4 mm; $5 \mu \mathrm{m}$; eluente: $\mathrm{MeOH} / \mathrm{H}_{2} \mathrm{O}$ (0,1\% TFA) 62:38; fluxo: $1,1 \mathrm{~mL} / \mathrm{min}$; detecção: UV $\lambda_{\max } 254 \mathrm{~nm}$ ]. A separação forneceu oito frações: Oket-1 (117,5 mg), Oket-2 (11,0 mg), Oket-3 (1,6 mg), Oket-4 (1,0 mg), Oket-5 (1,3 mg), Oket-6 (1,8 mg), Oket-7 (1,1 mg) e Oket-lav (13,3 mg), que foram analisadas por CLAE-UV-EM [coluna: Waters XTerra EM $\mathrm{C}_{18}$, de 2,1 x $50 \mathrm{~mm}$; 3,5 $\mu \mathrm{m}$; eluente: gradiente de $\mathrm{MeOH} / \mathrm{MeCN}$ 1:1 em $\mathrm{H}_{2} \mathrm{O}(0,1 \%$ TFA); fluxo: $0,5 \mathrm{~mL} / \mathrm{min}$; UV: espectro obtido entre 200 e $400 \mathrm{~nm}$; EM: $\mathrm{ESI}^{+}$, voltagem do cone $=25 \mathrm{~V}$ ].

As frações Oket-5, -6 e -7 foram reunidas devido à semelhança de seus perfis cromatográficos observados para estas amostras em
CLAE-UV-EM. A fração Oket-5 (4,2 mg), foi submetida a uma purificação por CLAE [coluna: Inertsil Phenyl (GL Sciences, Inc), de 250 x 4,6 mm; $5 \mu \mathrm{m}$; eluente: $\mathrm{MeOH} / \mathrm{H}_{2} \mathrm{O}(0,1 \%$ TFA) 6:4; fluxo: $0,8 \mathrm{~mL} / \mathrm{min}$; detecção: UV $\left.\lambda_{\max } 254 \mathrm{~nm}\right]$. A fração Oket-5b (1,0 mg) foi identificada por CLAE-UV-EM e por RMN de ${ }^{1} \mathrm{H}$ como sendo a substância 2,5,6-tribromo- $N$-metilgramina (13).

\section{2,5,6-tribromo- $N$-metilgramina (13)}

EM-ESI ${ }^{+}: m / z$ 422, 424, 426 e 428; UV: $\lambda_{\max } 230,296$ e $301 \mathrm{~nm}$; RMN de ${ }^{1} \mathrm{H}$ (DMSO- $\left.d_{6}, 400 \mathrm{MHz}\right): 8,29$ (s, H-4), 8,13 (s, H-7), 4,39 (s, 3H, $\left.\mathrm{CH}_{3}-8\right), 3,81$ (s, 2H, $\left.\mathrm{CH}_{2}-9\right), 2,78$ (s, 6H, $\left.\left(\mathrm{CH}_{3}\right)_{3}-9\right)$.

\section{Estudo químico do briozoário Zoobotryon verticillatum}

Colônias do briozoário Z. verticillatum ( $17 \mathrm{~g}$, peso úmido) foram coletadas em Cabo Frio, RJ, Brasil e preservadas em EtOH. Após remoção do EtOH de preservação, o briozoário foi re-extraído com $100 \mathrm{~mL}$ de $\mathrm{MeOH}$ em banho de ultrassom por $2 \mathrm{~min}$, e deixado em repouso durante $1 \mathrm{~h}$. Repetiu-se este procedimento mais duas vezes. A seguir, os $300 \mathrm{~mL}$ de $\mathrm{MeOH}$ utilizados na extração foram reunidos com o EtOH de preservação do animal e o solvente foi evaporado até redução do volume para aproximadamente $200 \mathrm{~mL}$. A suspensão hidroalcoólica foi submetida a uma partição líquido-líquido com hexano (4 x $200 \mathrm{~mL}$ ), resultando nos extratos metanólico (Zvme, 1,15 g) e hexânico (Zvhx, 93,7 mg).

O extrato Zvme foi submetido a uma separação por cromatografia em coluna pré-empacotada contendo sílica gel derivatizada com grupos $\mathrm{C}_{18}$ como fase estacionária ( $\left.10 \mathrm{~g}\right)$ e utilizando-se um gradiente de $\mathrm{MeOH}$ em $\mathrm{H}_{2} \mathrm{O}$ como eluente $\left(\mathrm{H}_{2} \mathrm{O} 100 \%, \mathrm{H}_{2} \mathrm{O} / \mathrm{MeOH}\right.$ 8:2, 6:4, 4:6 e $\mathrm{MeOH} 100 \%)$. Análises por $\mathrm{CCD}\left(\mathrm{CH}_{2} \mathrm{Cl}_{2} / \mathrm{MeOH}\right.$ 9:1 e 7:3 como eluentes; ácido fosfomolíbdico, ninidrina e Dragendorff como reveladores) das diversas frações obtidas permitiram que fossem reunidas em seis novas frações: Zvme-1 (930 mg), Zvme-2 (14,3 mg), Zvme-3 (8,0 mg), Zvme-4 (3,8 mg), Zvme-5 (42,3 mg) e Zvme-6 (52,2 mg), as quais foram analisadas por CLAE-UV-EM [coluna: Waters XTerra $\mathrm{C}_{18}$, de 2,1 x $50 \mathrm{~mm}$; 3,5 $\mu$ m; eluente: gradiente de $\mathrm{MeOH} / \mathrm{MeCN}$ 1:1 em $\mathrm{H}_{2} \mathrm{O}(0,1 \%$ TFA); fluxo: $0,5 \mathrm{~mL} / \mathrm{min}$; UV: espectro obtido entre 200 e 400 nm; EM: $\mathrm{ESI}^{+}$, voltagem do cone $\left.=25 \mathrm{~V}\right]$.

Após a análise por CLAE-UV-EM, a fração Zvme-5 foi submetida a uma purificação por CLAE [coluna: Waters Phenyl $\mu$ Bondapak, de 300 x 3,9 mm; $10 \mu \mathrm{m}$; eluente: gradiente de $\mathrm{MeOH}$ em $\mathrm{H}_{2} \mathrm{O}(0,1 \%$ TFA) ; fluxo: 1,0 mL/min; detecção: UV $\lambda_{\max } 254 \mathrm{~nm}$ ] obtendo-se cinco novas frações, Zvme-5a (5,4 mg), Zvme-5b (2,5 mg), Zvme$5 \mathrm{c}(18,3 \mathrm{mg})$, Zvme-5d (18 mg) e Zvme-5e (2,3 mg). Estas frações foram novamente analisadas em sistema CLAE-UV-EM, nas mesmas condições citadas acima.

A fração Zvme-5b foi submetida a uma nova purificação por CLAE (coluna: Waters Symmetry $\mathrm{C}_{18}$, de 75 x 4,6 mm; 3,5 $\mu \mathrm{m}$; eluente: $\mathrm{MeOH} / \mathrm{H}_{2} \mathrm{O} 57: 43$ (0,1\% TFA); fluxo: $0,7 \mathrm{~mL} / \mathrm{min}$; detecção: UV $\lambda_{\max } 254 \mathrm{~nm}$ ), obtendo-se o alcaloide 2,3,5-tribromo- $N$-metilgramina (13) na fração Zvme-5b2 (1,7 mg).

\section{AGRADECIMENTOS}

Ao Conselho Nacional de Desenvolvimento Científico e Tecnológico (CNPq-Brasil) e à Fundação de Amparo à Pesquisa do Estado de São Paulo (FAPESP) pelo apoio financeiro, esta última através de projetos temáticos (2005/60175-2 e 2010/50190-2) no âmbito do programa BIOTA/BIOprospecTA, bem como ao Instituto Brasileiro do Meio Ambiente e dos Recursos Naturais Renováveis (IBAMA) e CNPq, pelas autorizações de coleta (SISBIO 26142-1) e acesso ao patrimônio genético (010553/2011-8). Agradecemos também a C. A. Cunha (CaboFrioSub) pela ajuda na coleta de exemplares 
de $O$. zoobotryon. V. Padula é bolsista de doutorado no exterior do CNPq-Brasil e DAAD (German Academic Exchange Service).

\section{REFERÊNCIAS}

1. Avila, C.; Ocean. Mar. Biol. Annu. Rev. 1995, 33, 487.

2. Cimino, G.; Ghiselin, M.T. Em Marine Chemical Ecology; McClintock, J. B.; Baker, B. J., eds.; CRC Press: Boca Raton, 2001, chap. 3.

3. Kubanek, J.; Andersen, R. J.; J. Nat. Prod. 1999, 62, 777.

4. Fontana, A.; Cavaliere, P.; Wahidulla, S.; Naik, C. G.; Cimino, G.; Tetrahedron 2000, 56, 7305.

5. Uddin, M. H.; Otsuka, M.; Muroi, T.; Ono, A.; Hanif, N.; Matsuda, S.; Higa, T.; Tanaka, J.; Chem. Pharm. Bull. 2009, 57, 885.

6. Kernan, M. R.; Molinski, T. F.; Faulkner, D. J.; J. Org. Chem. 1988, 53 , 5014.

7. Sakio, Y.; Hirano, Y. J.; Hayashi, M.; Komyiama, K.; Ishibashi, M.; J. Nat. Prod. 2001, 64, 726.

8. Miyamoto, T.; Sakamoto, K.; Amano, H.; Arakawa, Y.; Nagarekawa, Y.; Komori, T.; Higushi, R.; Sasaki, T.; Tetrahedron 1999, 55, 9133.

9. Franks, A.; Haywood, P.; Holmstron, C.; Egan, S.; Kjelleberg, S.; Kumar, N.; Molecules 2005, 10, 1286.

10. Kojiri, K.; Nakajima, S.; Suzuki, H.; Okura, A.; Suda, H.; J. Antibiot. 1993, 46, 1799.

11. Carbone, M.; Irace, C.; Costagliola, F.; Castelluccio, F.; Villani, G.; Calado, G.; Padula, V.; Cimino, G.; Cervera, J. L.; Santamaria, R.; Gavagnin, M.; Bioorg. Med. Chem. Lett. 2010, 20, 2668.

12. Pinkerton, D. M. ; Banwell, M. G.; Garson, M. J.; Kumar, N.; Moraes, M. O.; Cavalcanti, B. C.; Barros, F. W. A.; Pessoa, C.; Chem. Biodiv. 2010, 7, 1311 .
13. Granato, A. C.; Oliveira, J. H. H. L.; Seleghim, M. H. R.; Berlinck, R. G S.; Macedo, M. L.; Ferreira, A. G.; Rocha, R. M.; Hajdu, E.; Peixinho, S.; Pessoa, C. O.; Moraes, M. O.; Cavalcanti, B. C.; Quim. Nova 2005 , $28,192$.

14. Cavalcanti, B. C.; Nobre Júnior, H. V.; Seleghim, M. H. R.; Berlinck, R. G. S.; Cunha, G. M. A.; Moraes, M. O.; Pessoa, C.; Chem.-Biol. Interact. 2008, 174, 155.

15. McPhail, K.; Davies-Coleman, M. T.; Coetzee, P.; J. Nat. Prod. 1998, 61,961 .

16. Avila C.; Cimino, G.; Fontana, A.; Gavagnin, M.; Ortea, J.; Trivellone, E.; J. Chem. Ecol. 1991, 17, 625

17. Fontana, A.; Avila, C.; Martinez, E.; Ortea, M.; Trivellone, J.; Cimino, G.; J. Chem. Ecol. 1993, 19, 339.

18. Wirtz, P.; Canning-Clode, J.; J. Aquat. Inv. 2009, 4, 669.

19. Sato, A.; Fenical, W.; Tetrahedron Lett. 1983, 24, 481.

20. Gandolfi, R. C.; Medina, M. B.; Berlinck, R. G. S.; Lira, S. P.; Galetti, F. C. S.; Silva, C. L.; Veloso, K.; Ferreira, A. G.; Hajdu, E.; Peixinho, S.; Quim. Nova 2010, 33, 1853.

21. Carté, B.; Faulkner, D. J.; J. Org. Chem. 1983, 48, 2314.

22. Silverstein, R. M.; Webster, F. X.; Identificação Espectrométrica de Compostos Orgânicos, LTC editora: Rio de Janeiro, $7^{\text {a }}$ ed., 2007.

23. Pinkerton, D. M.; Banwell, M. G.; Willis, A.C.; Org. Lett. 2007, 9, 5127.

24. Pola, M.; Cervera, J. L.; Gosliner, T. M.; J. Mar. Biol. Assoc. 2005, 85, 979.

25. Blackman, A. J.; Li, C. ; Aust. J. Chem. 1994, 47, 1625.

26. Franks, A.; Haywood, P.; Holmström, C.; Egan, S.; Kjelleberg, S.; Kumar, N.; Molecules 2005, 10, 1286.

27. Grode, S. H.; Cardellina II, J. H.; J. Nat. Prod. 1984, 47, 76. 
METABÓLITOS SECUNDÁRIOS DOS NUDIBRÂNQUIOS Tambja stegosauriformis, Hypselodoris lajensis E Okenia zoobotryon E DOS briozoários Zoobotryon verticillatum E Bugula dentata DA COSTA DO BRASIL

Fábio R. Pereira e Roberto G. S. Berlinck*

Instituto de Química de São Carlos, Universidade de São Paulo, CP 780, 13560-970 São Carlos - SP, Brasil

Edson Rodrigues Filho, Katyuscya Veloso e Antonio G. Ferreira

Departamento de Química, Universidade Federal de São Carlos, CP 676, 13560-970 São Carlos - SP, Brasil

Vinicius Padula

Zoologische Staatssammlung München, Mollusca Sektion, Münchhausenstr. 21, 81247, München, Germany

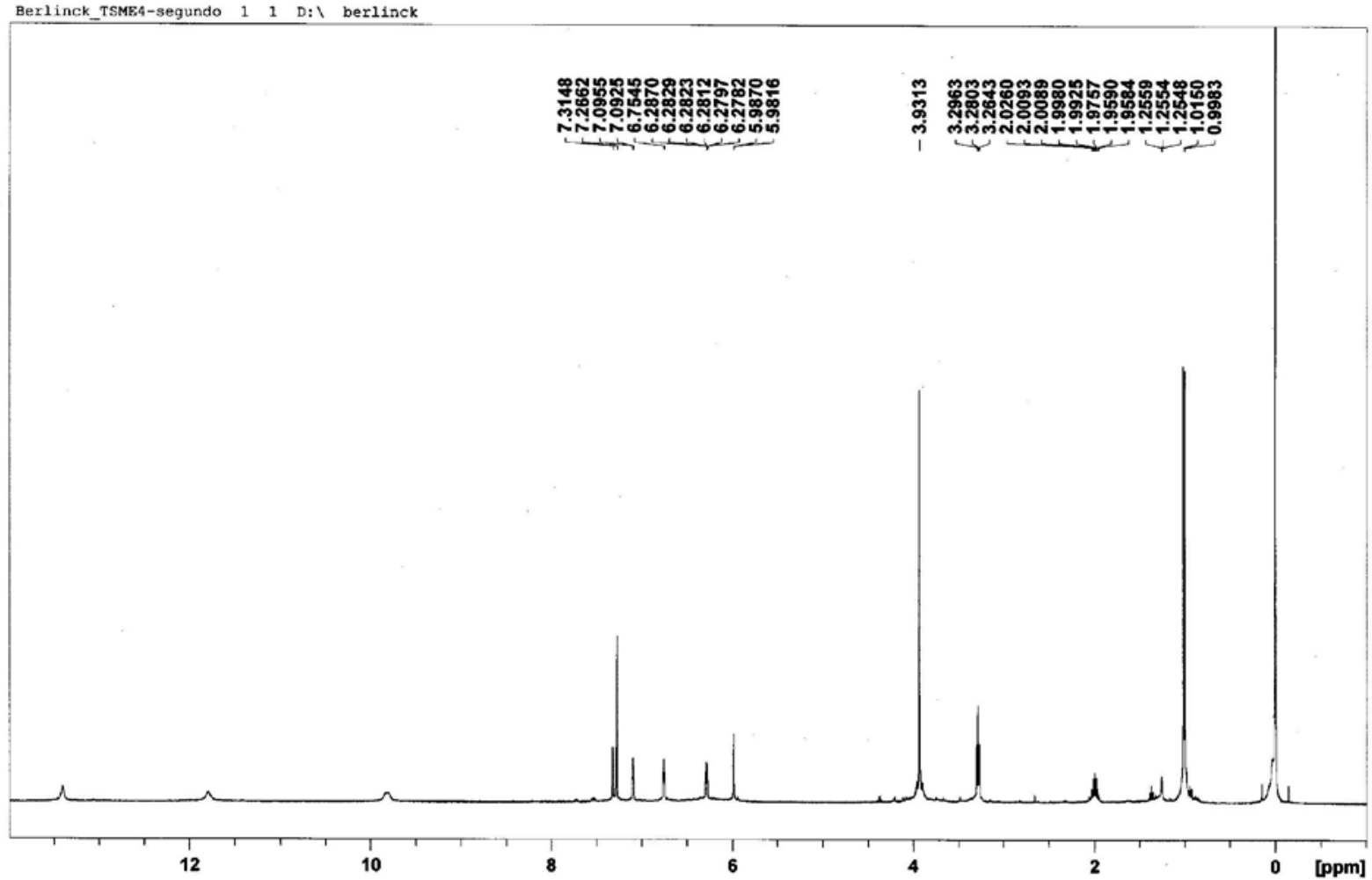

Figura 1S. Espectro de $\mathrm{RMN}^{1} \mathrm{H}\left(\mathrm{CDCl}_{3}, 400 \mathrm{MHz}\right)$ da tambjamina $\mathrm{C}(3)$ isolada de T. stegosauriformis
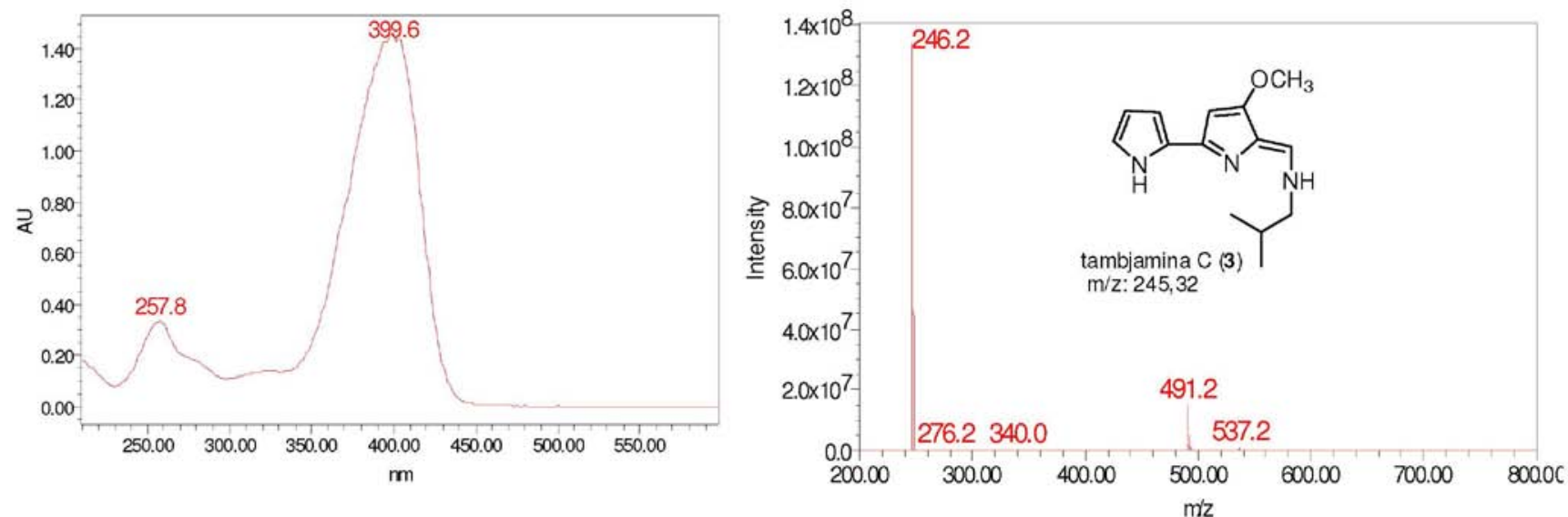

Figura 2S. Espectros no ultravioleta e de massas $\left(\mathrm{ESI}^{+}\right)$da tambjamina C (3) isolada de T. stegosauriformis

*e-mail: rgsberlinck@iqsc.usp.br

\#Artigo em homenagem ao Prof. Otto R. Gottlieb (31/8/1920-19/6/2011) 

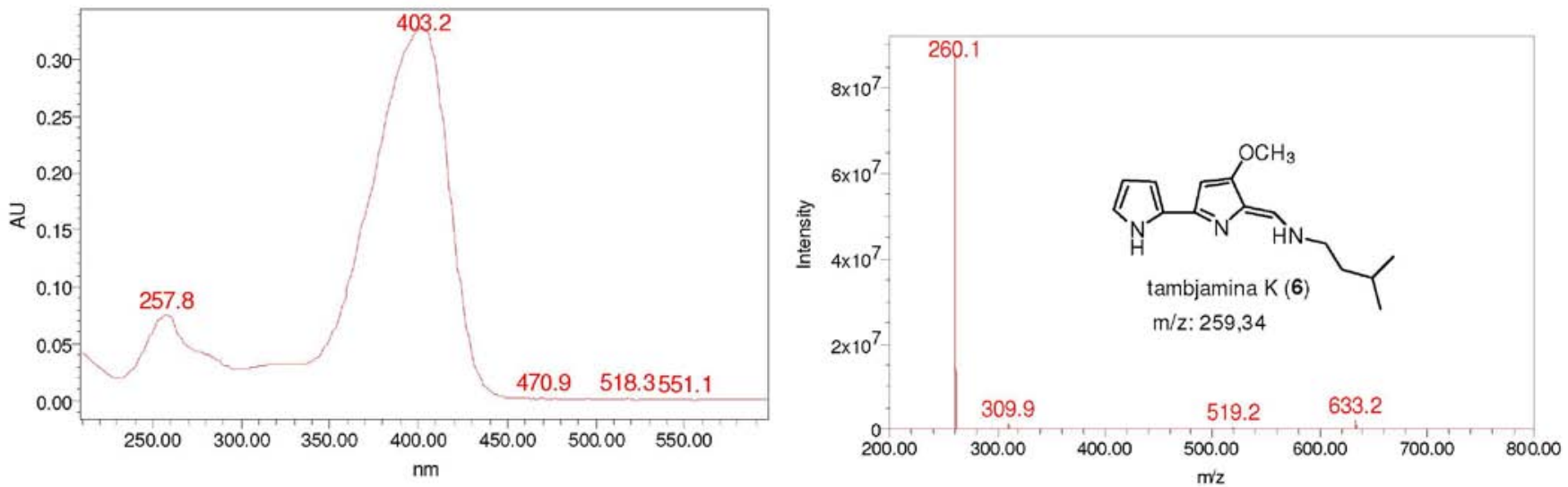

Figura 3S. Espectros no ultravioleta e de massas $\left(\mathrm{ESI}^{+}\right)$da tambjamina $\mathrm{K}(\mathbf{6})$ isolada de T. stegosauriformis

Met Aminas

EDS_TSME6_LCDI260b 292 (6.210) Sm (Mn, 4x0.80); Cm (257:364-(47:114+565:624))

100

$100-$

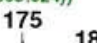

1: Daughters of 260 ES+

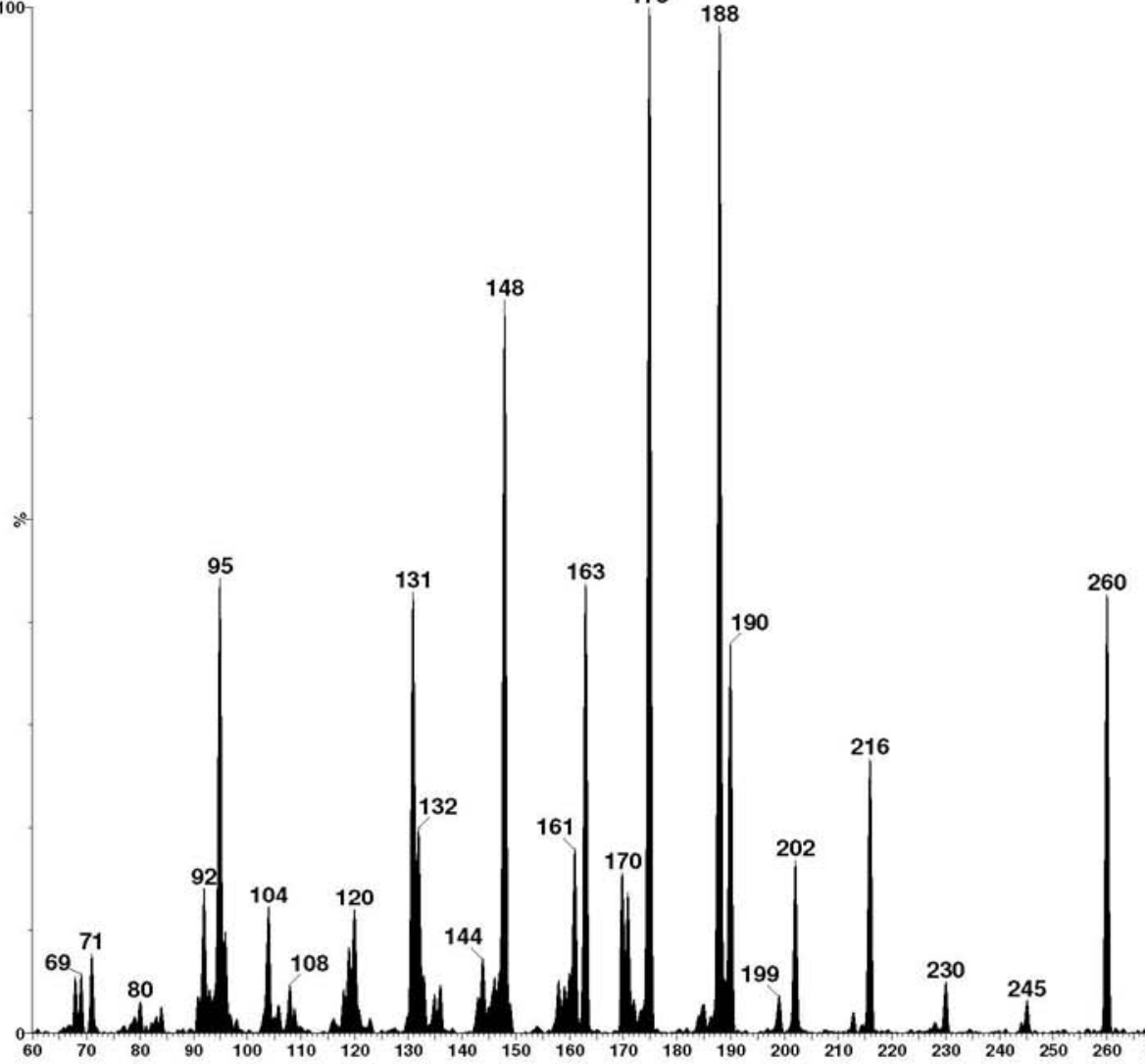

Figura 4S. Espectro de massas tipo MS/MS $\left(\right.$ ESI $\left.^{+}\right)$da tambjamina $K(\mathbf{6})$ isolada de T. stegosauriformis 
Tsme-2b1-1 p1341 in DMSO-d6 AV600.cp

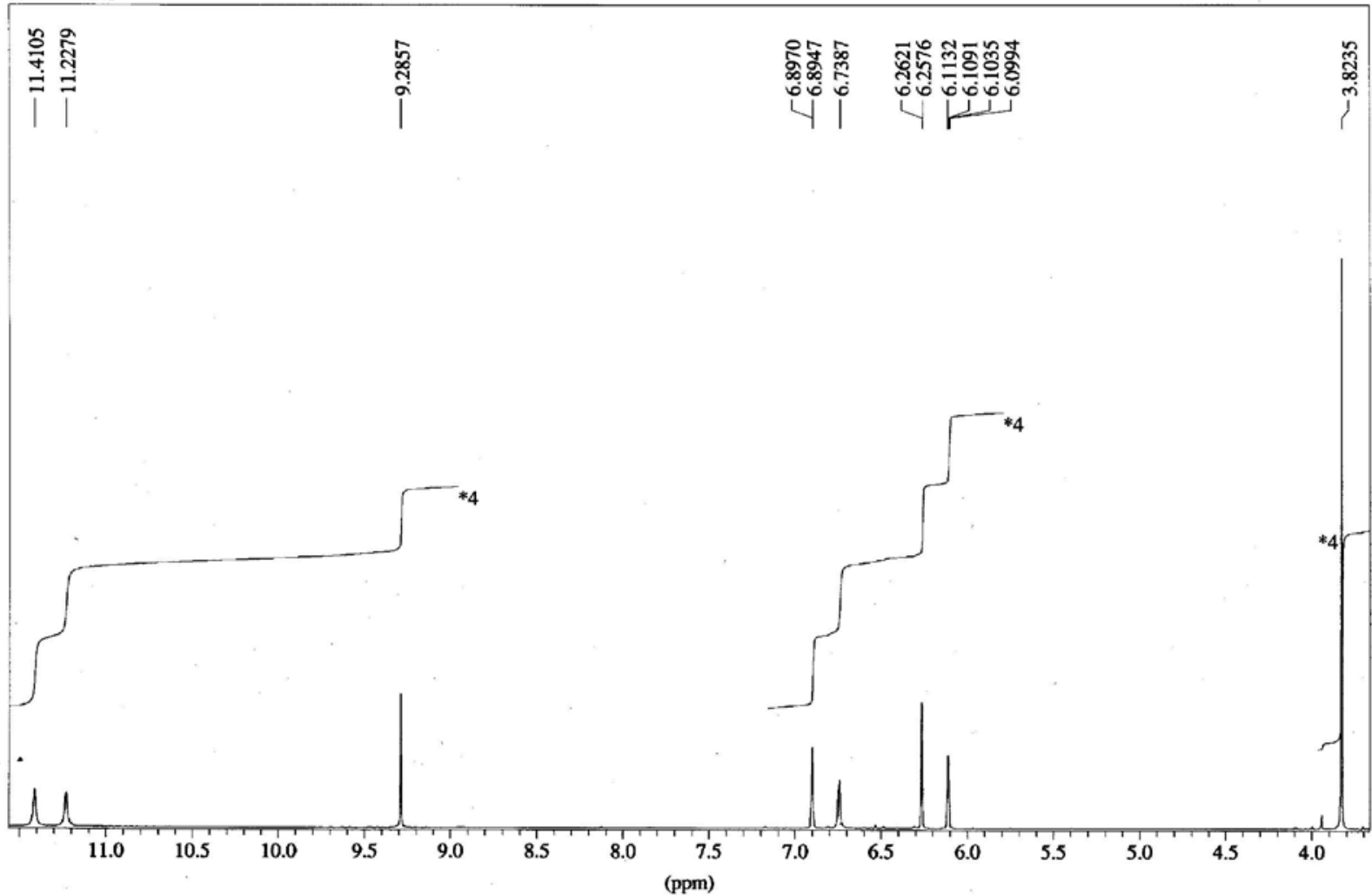

Figura 5S. Espectro de $\mathrm{RMN}^{-1} \mathrm{H}\left(\mathrm{DMSO}-\mathrm{d}_{6}, 600 \mathrm{MHz}\right)$ do aldeído da tambjamina A (7) isolada de T. stegosauriformis

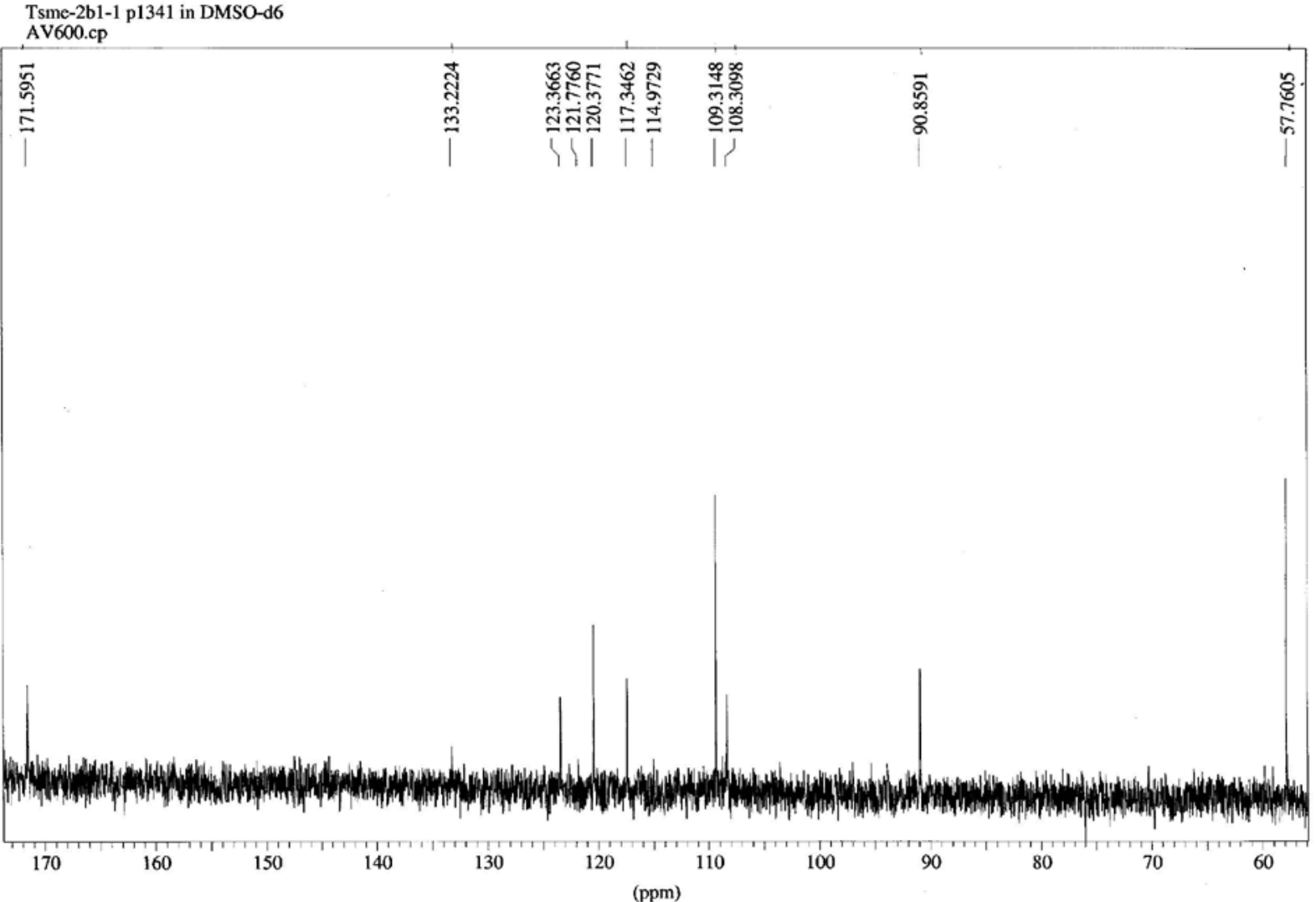

Figura 6S. Espectro de $\mathrm{RMN}_{-}{ }^{13} \mathrm{C}\left(\mathrm{DMSO}-\mathrm{d}_{6}, 125 \mathrm{MHz}\right)$ do aldeído da tambjamina A (7) isolada de T. stegosauriformis 

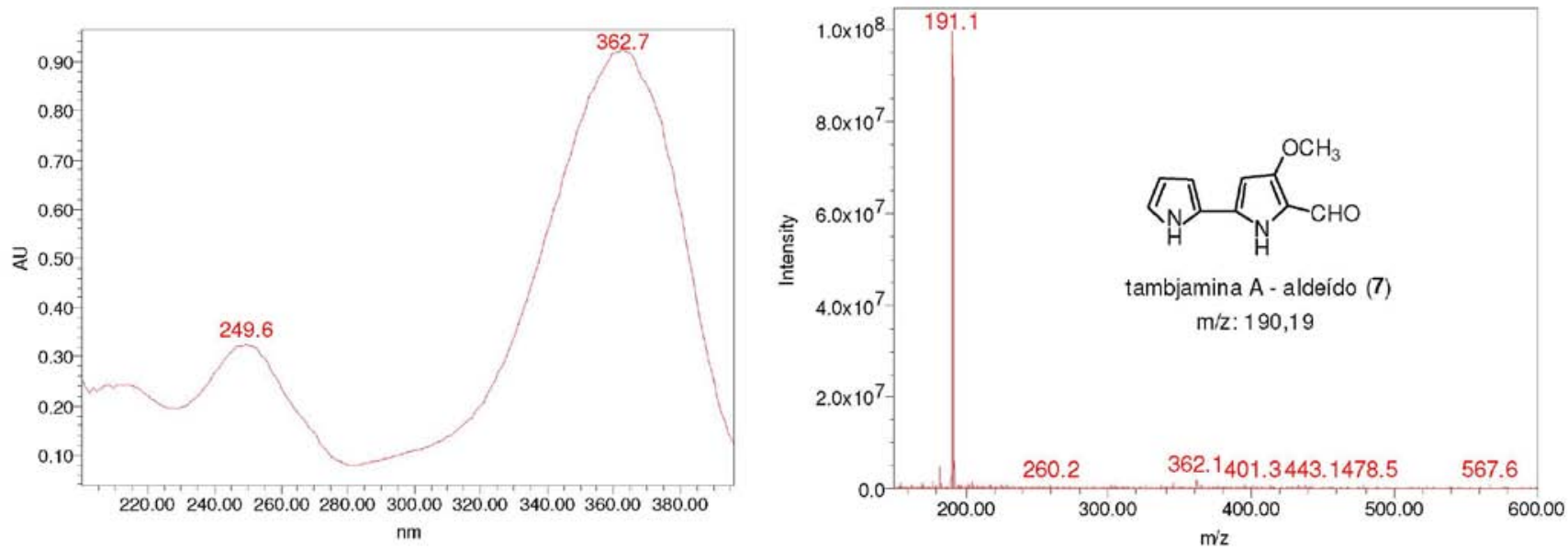

Figura 7S. Espectros no ultravioleta e de massas $\left(\mathrm{ESI}^{+}\right)$do aldeído da tambjamina A (7) isolada de T. stegosauriformis

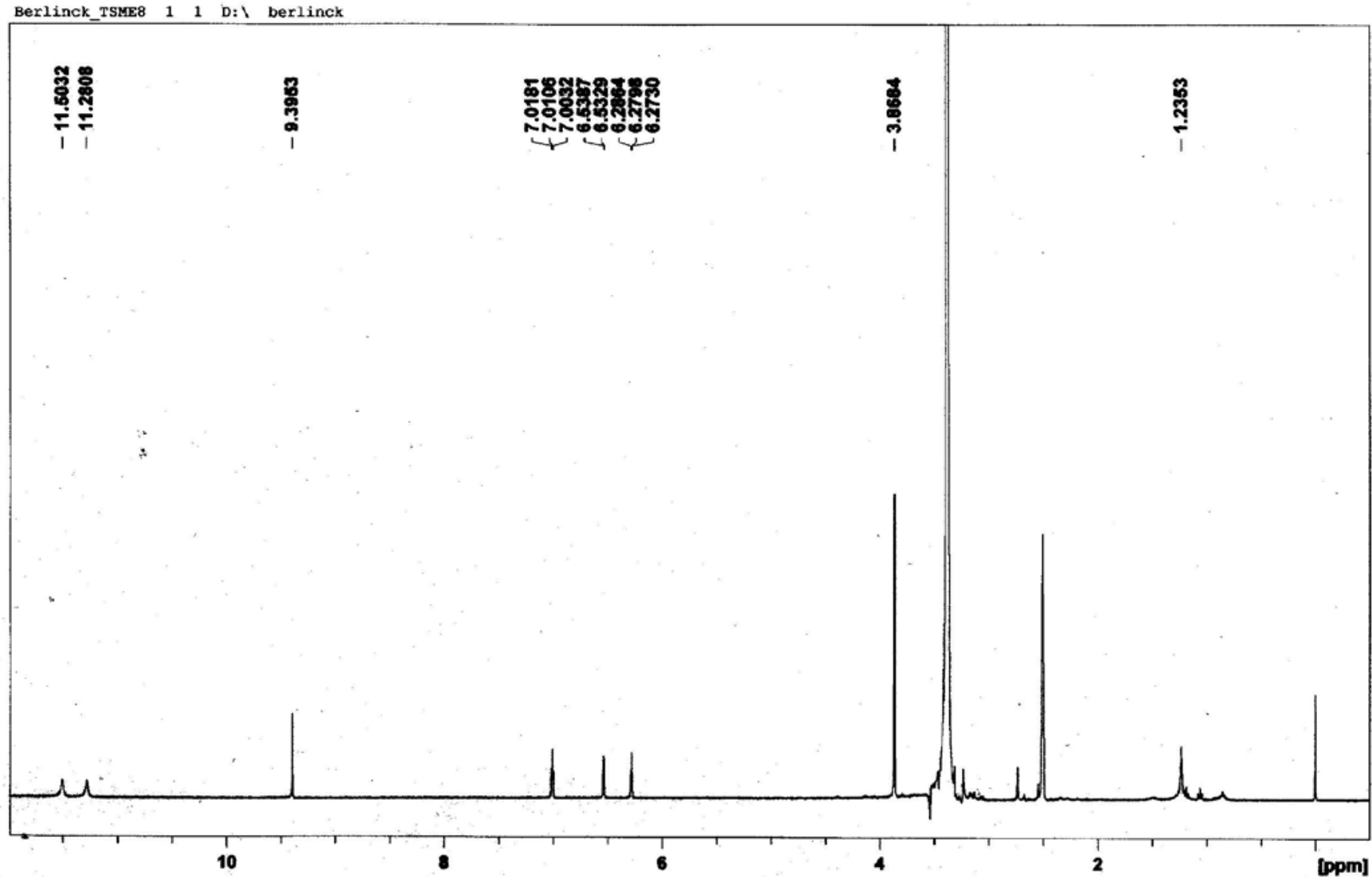

Figura 8S. Espectro de massas tipo MS/MS $\left(\mathrm{ESI}^{+}\right)$do aldeído da tambjamina A (7) isolada de T. stegosauriformis 


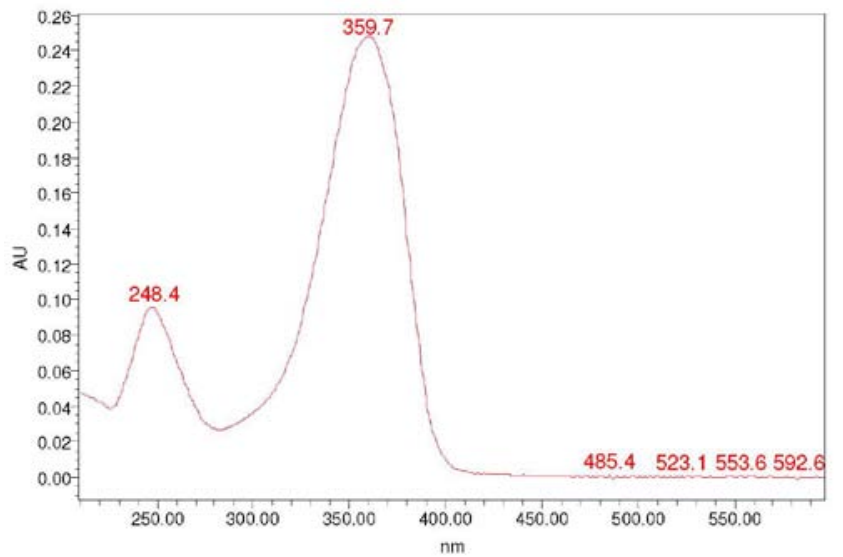

Figura 9S. Espectro de $R M N-{ }^{l} H\left(D M S O-d_{\sigma}, 400 \mathrm{MHz}\right)$ do aldeído da tambjamina B (8) isolada de T. stegosauriformis

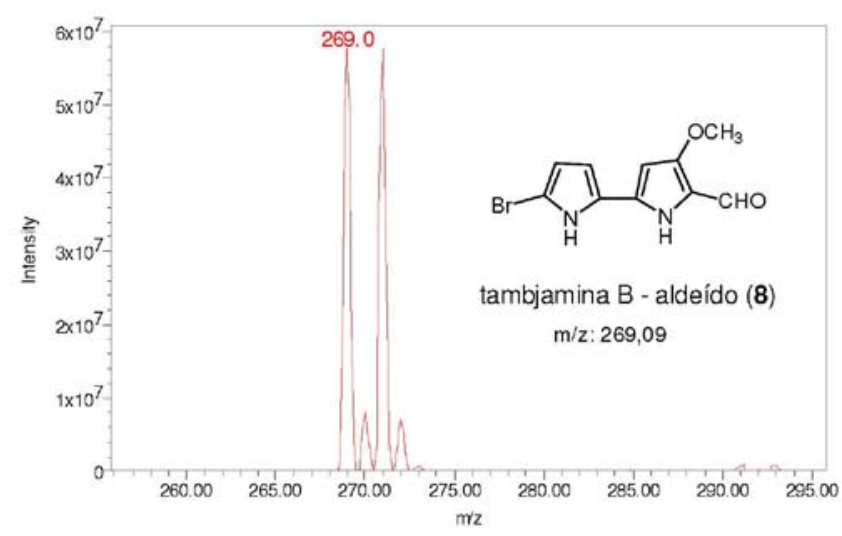

Figura 10S. Espectros no ultravioleta e de massas $\left(E S I^{+}\right)$do aldeído da tambjamina $B(8)$ isolada de T. stegosauriformis

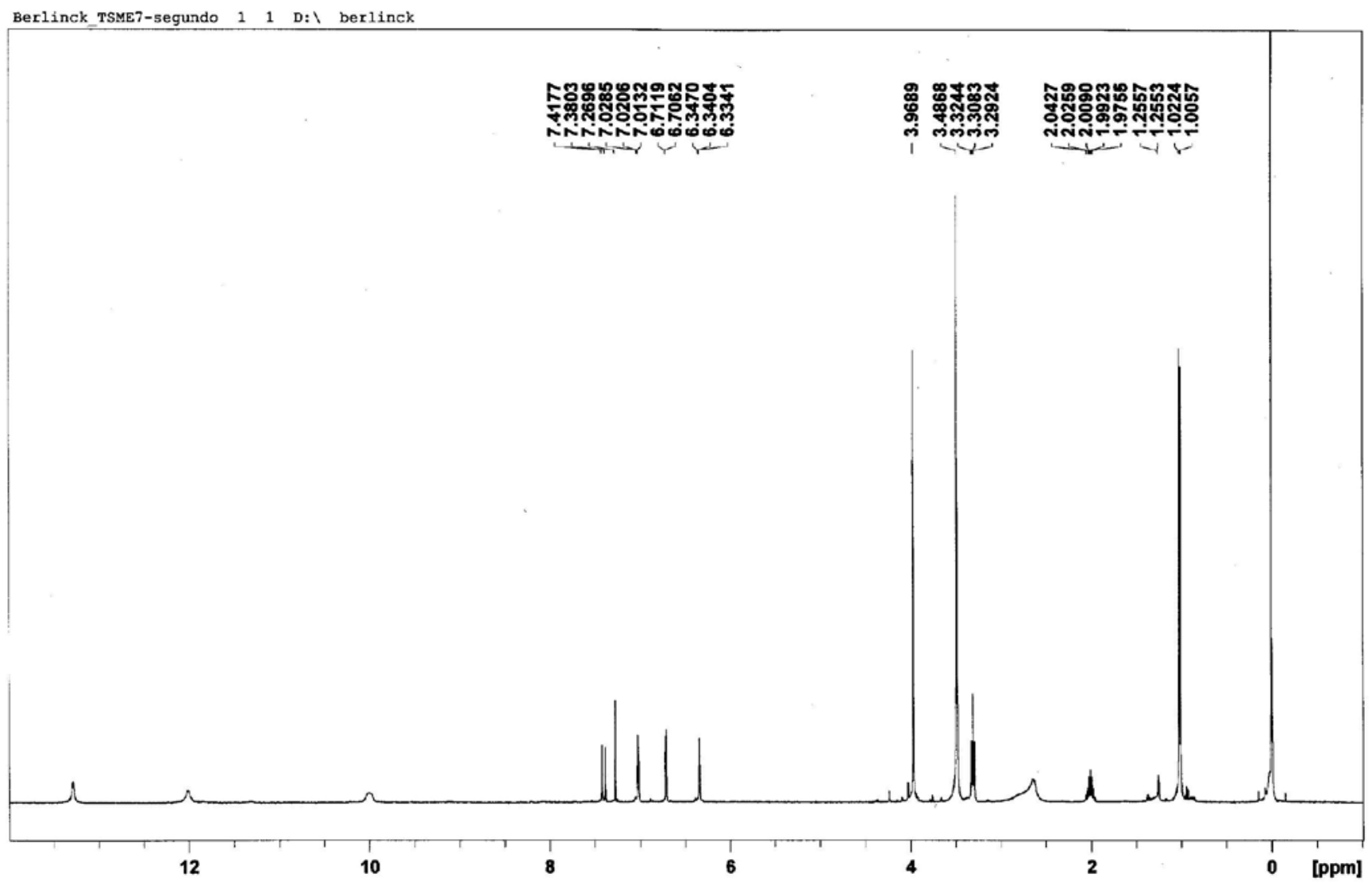

Figura 11S. Espectro de massas tipo MS/MS $\left(\right.$ ESI $\left.^{+}\right)$do aldeído da tambjamina B (7) isolada de T. stegosauriformis 


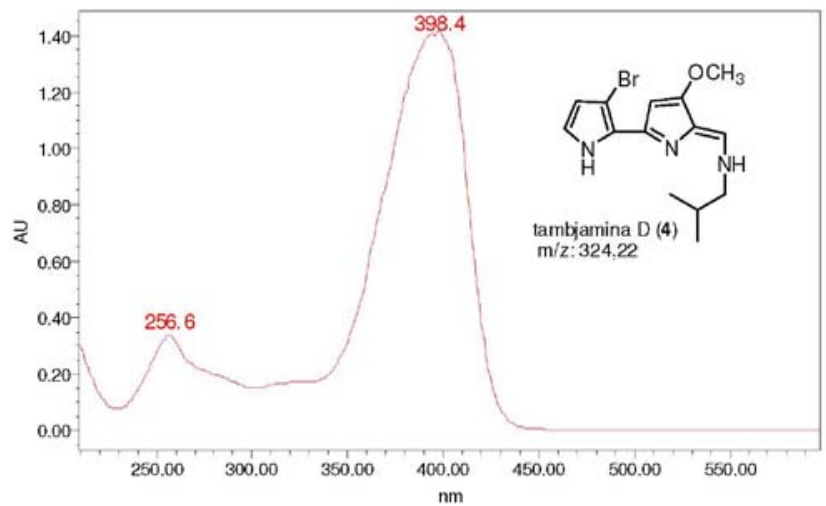

Figura 12S. Espectro de $\mathrm{RMN}^{-}{ }^{-} \mathrm{H}\left(\mathrm{CDCl}_{3}, 400 \mathrm{MHz}\right)$ da tambjamina $\mathrm{D}(4)$ isolada de T. stegosauriformis
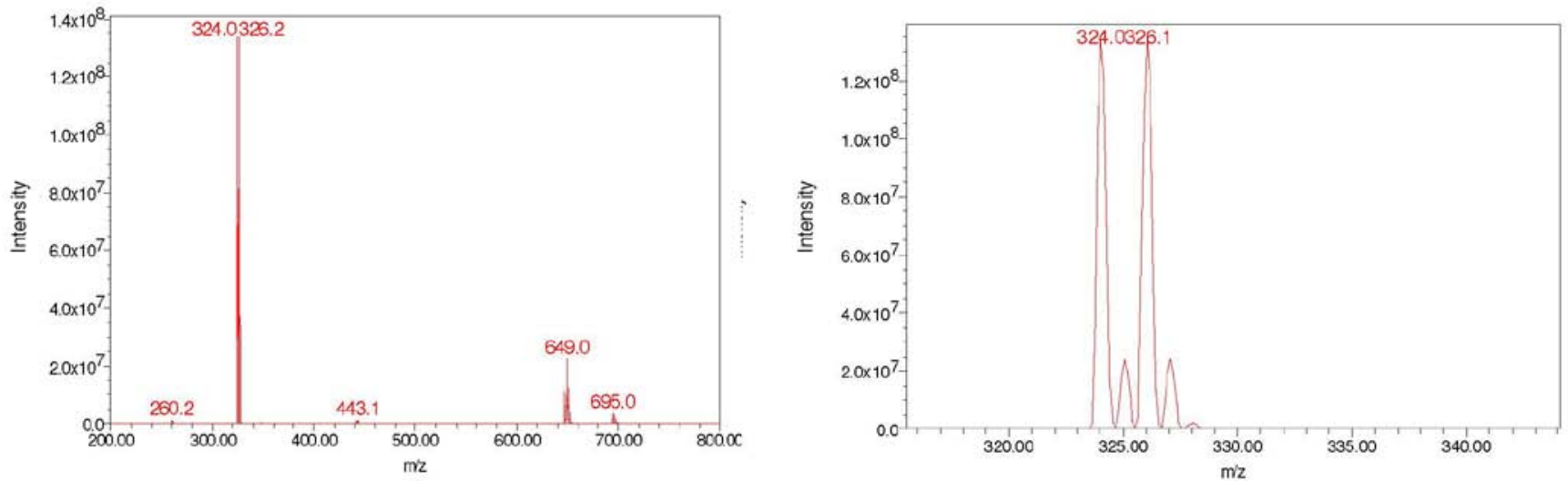

Figura 13S. Espectros no ultravioleta e de massas $\left(E I^{+}\right)$da tambjamina $D(4)$ isolada de T. stegosauriformis

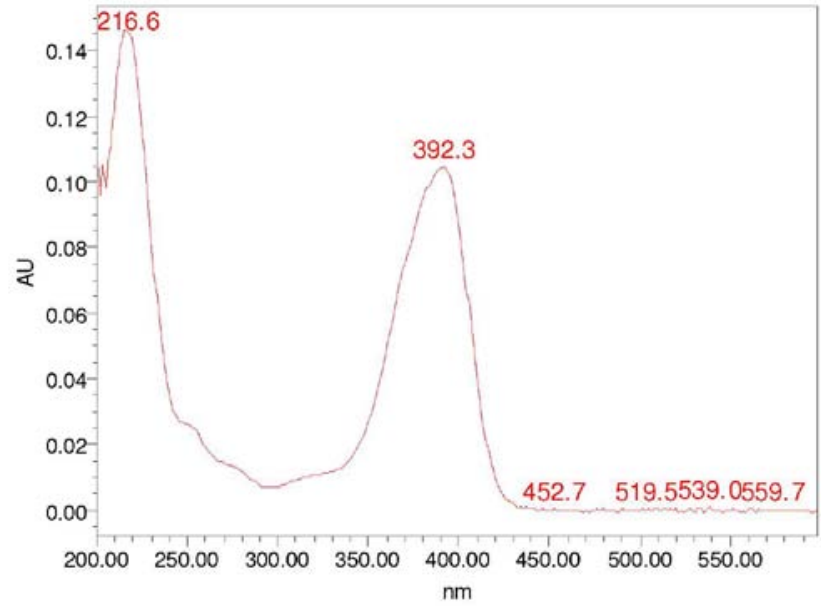

Figura 14S. Espectro de massas tipo MS/MS (ESI+) da tambjamina D (4) isolada de T. stegosauriformis

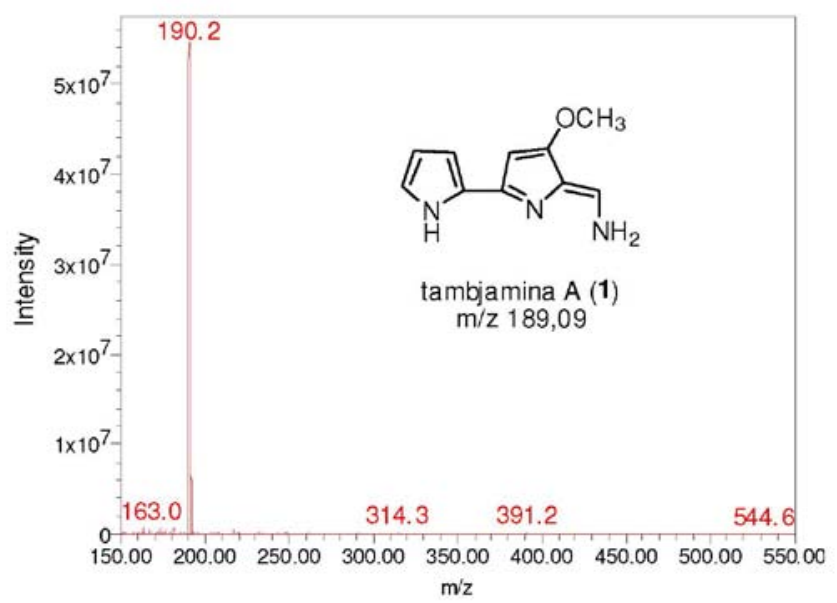

Figura 15S. Espectros no ultravioleta e de massas $\left(E^{+} I^{+}\right)$da tambjamina A (1) isolada de B. dentata 


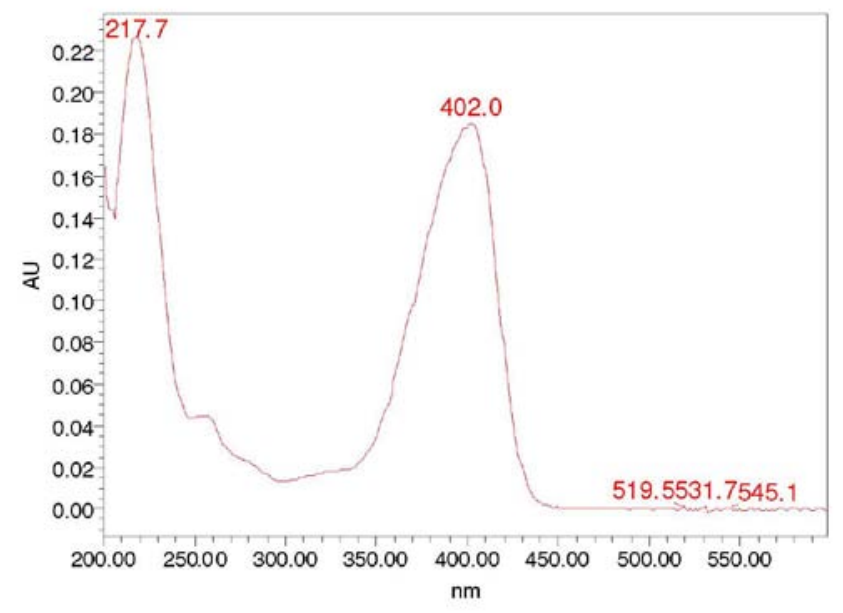

Figura 16S. Espectro de $\mathrm{RMN}^{-}{ }^{\mathrm{H}} \mathrm{H}\left(\mathrm{CDCl}_{3}, 400 \mathrm{MHz}\right)$ da tambjamina A (1) isolada de B. dentata

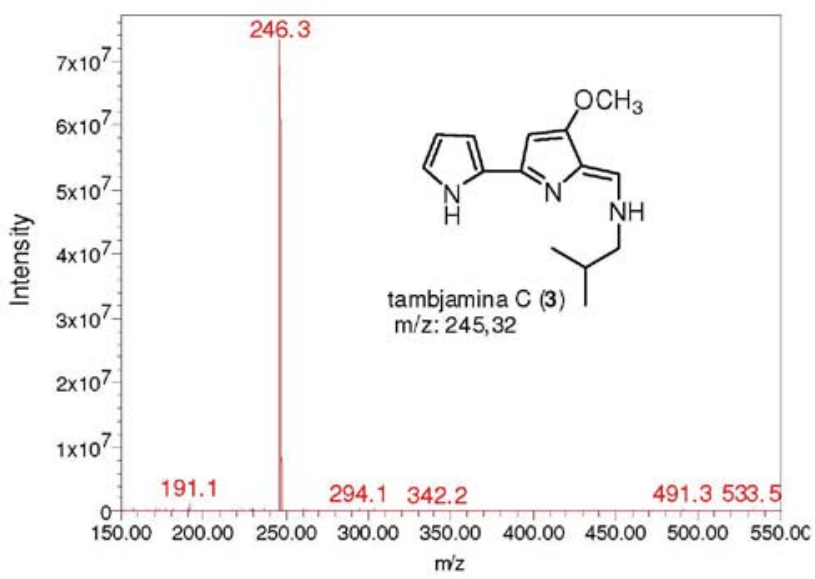

Figura 17S. Espectros no ultravioleta e de massas $\left(\right.$ ESI $\left.^{+}\right)$da tambjamina $C$ (3) isolada de B. dentata

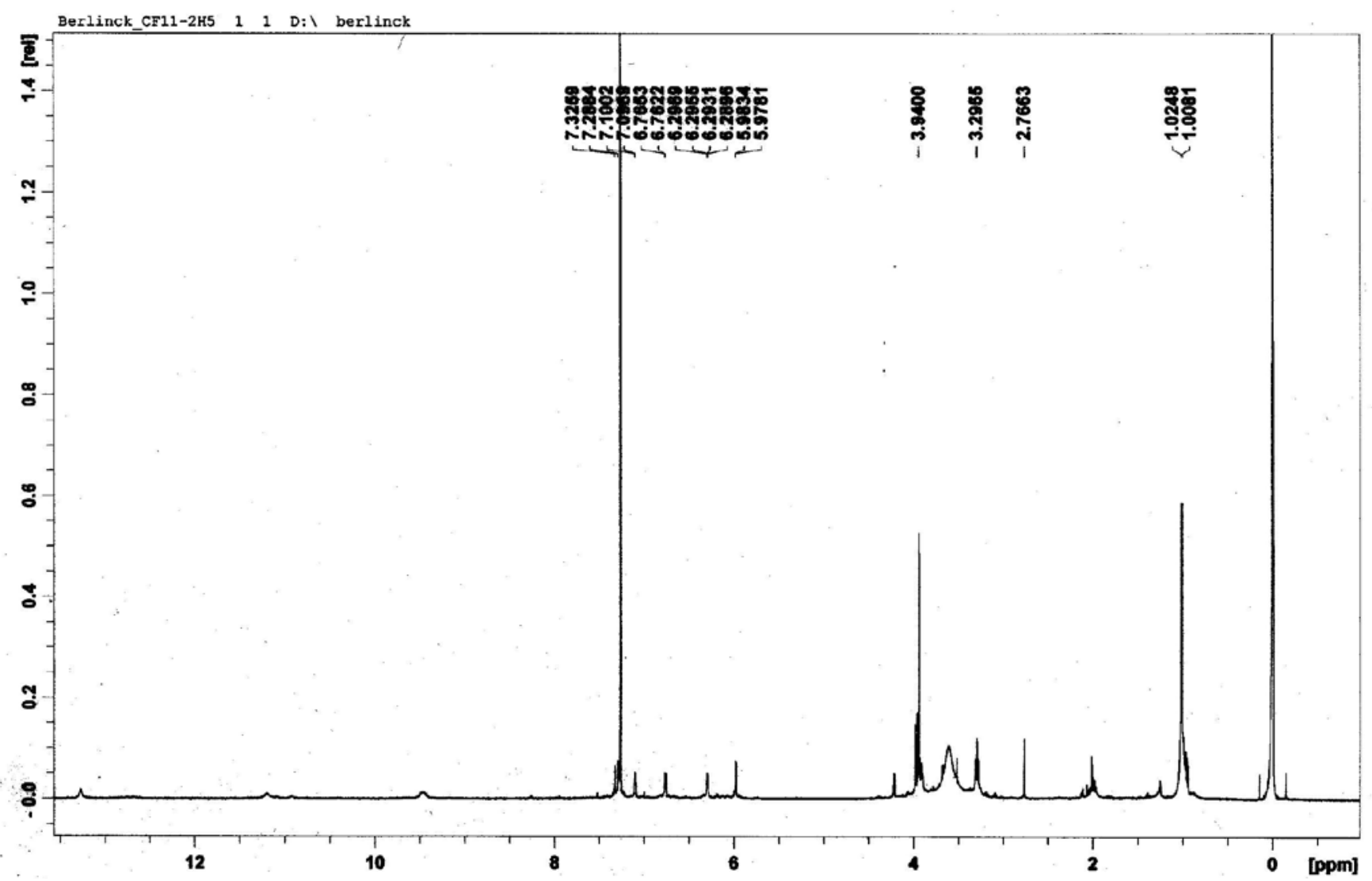

Figura 18S. Espectro de $\mathrm{RMN}^{-}{ }^{1} \mathrm{H}\left(\mathrm{CDCl}_{3}, 400 \mathrm{MHz}\right)$ da tambjamina $\mathrm{C}(3)$ isolada de B. dentata 


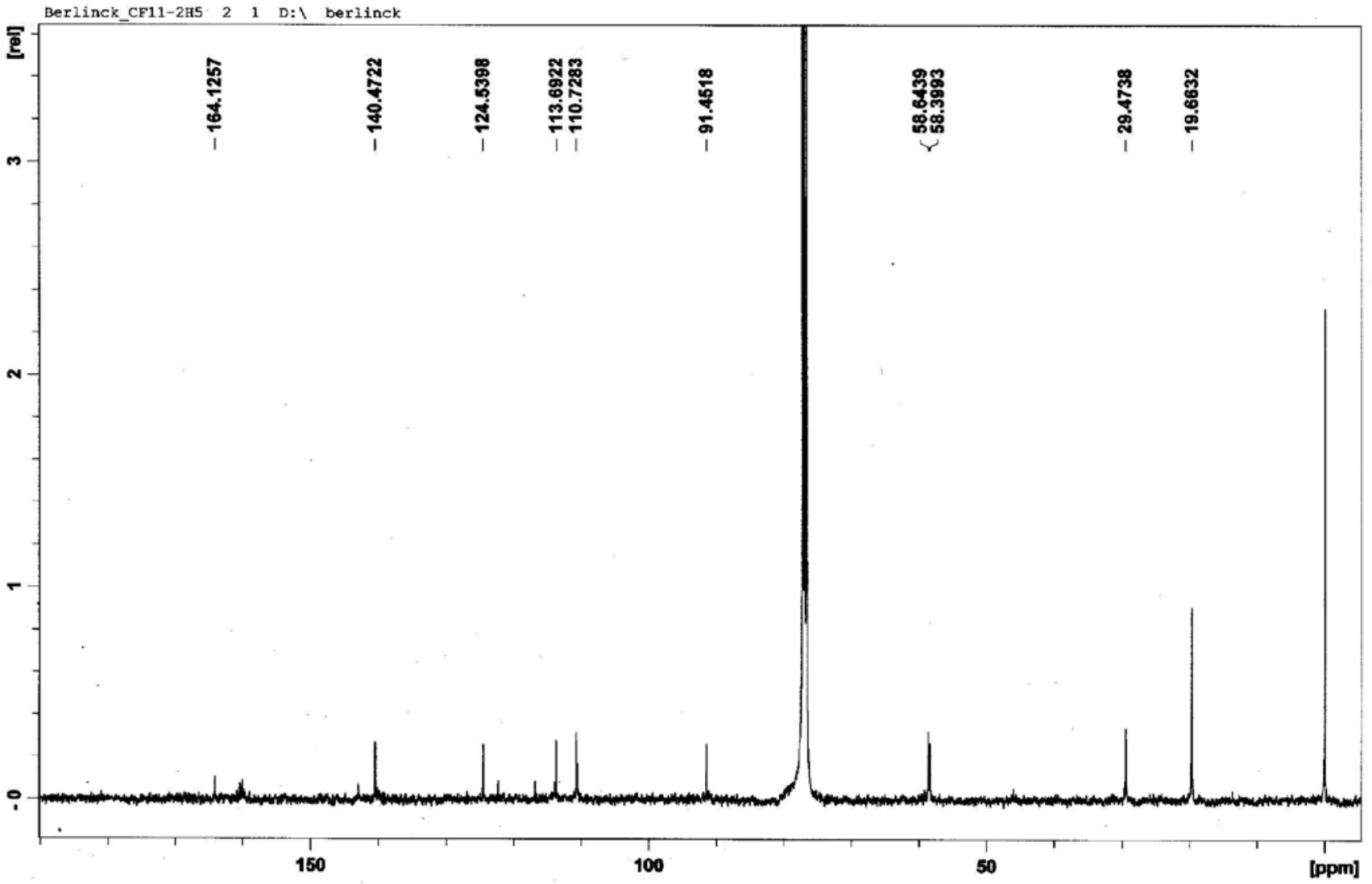

Figura 19S. Espectro de $\mathrm{RMN}_{-}{ }^{13} \mathrm{C}\left(\mathrm{CDCl}_{3}, 100 \mathrm{MHz}\right)$ da tambjamina $\mathrm{C}(3)$ isolada de B. dentata
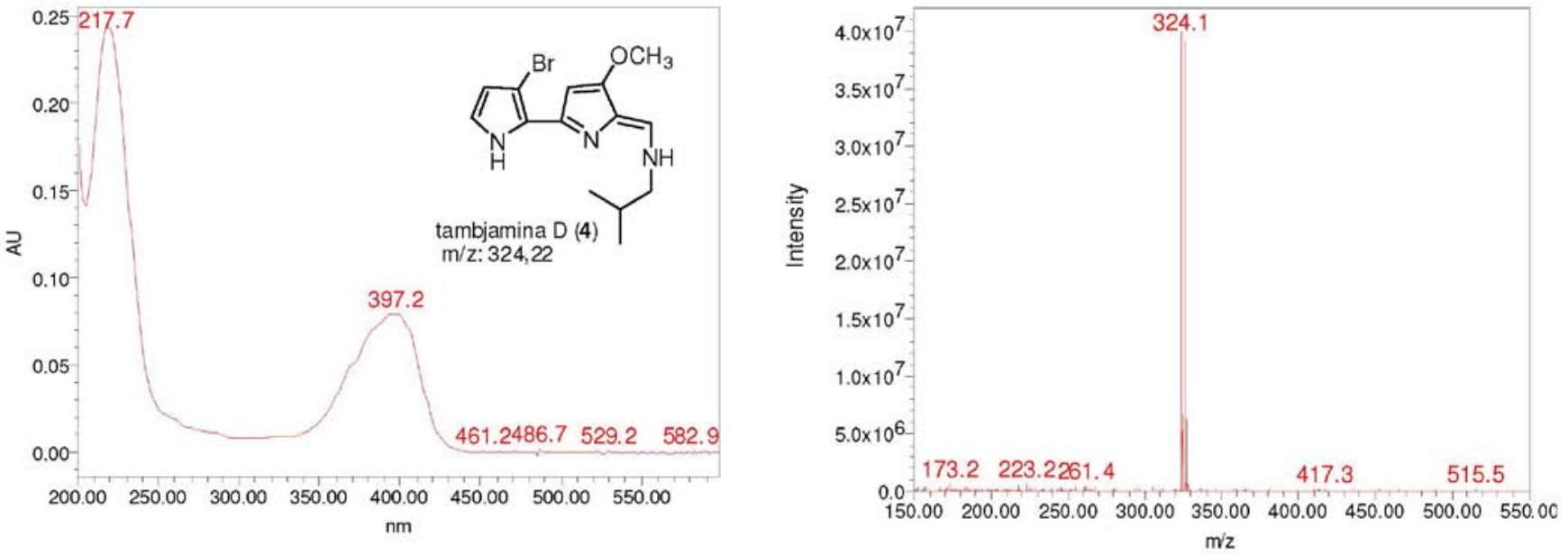

Figura 20S. Espectros no ultravioleta e de massas $\left(E S I^{+}\right)$da tambjamina $D(4)$ isolada de B. dentata 


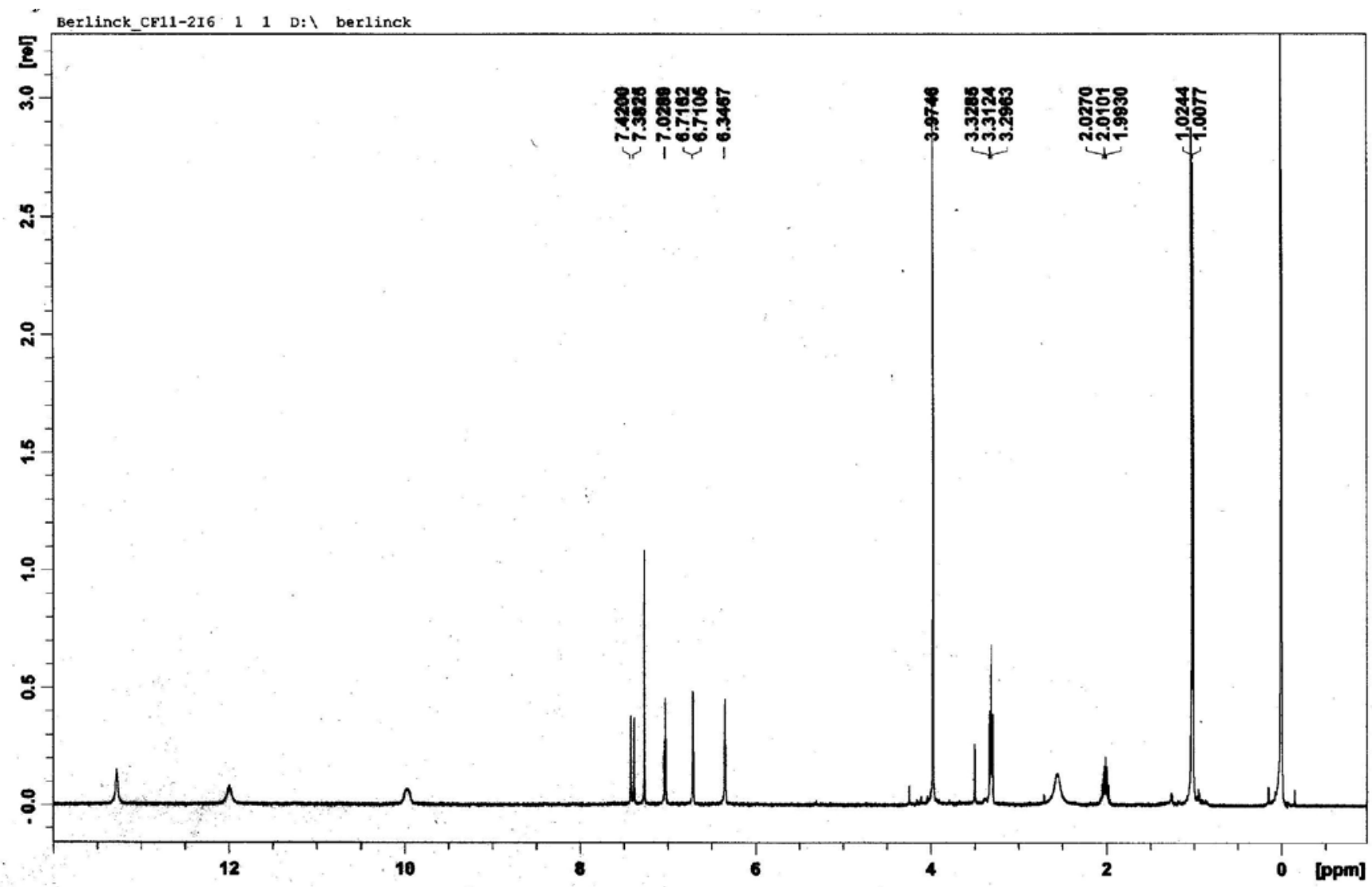

Figura 21S. Espectro de $\mathrm{RMN}^{-1} \mathrm{H}\left(\mathrm{CDCl}_{3}, 400 \mathrm{MHz}\right)$ da tambjamina $\mathrm{D}$ (4) isolada de B. dentata

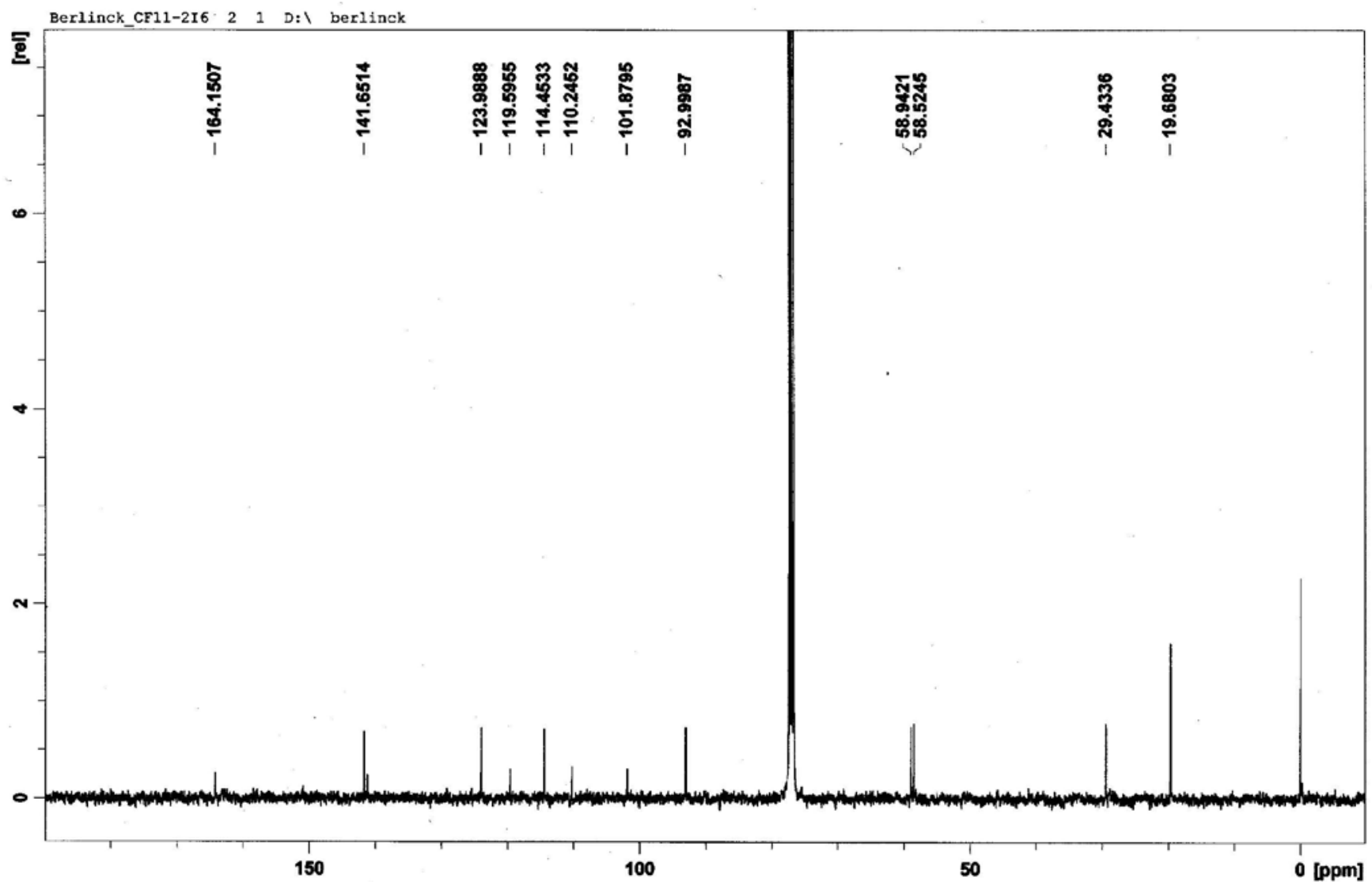

Figura 22S. Espectro de $\mathrm{RMN}^{-13} \mathrm{C}\left(\mathrm{CDCl}_{3}, 100 \mathrm{MHz}\right)$ da tambjamina $\mathrm{D}(4)$ isolada de B. dentata 

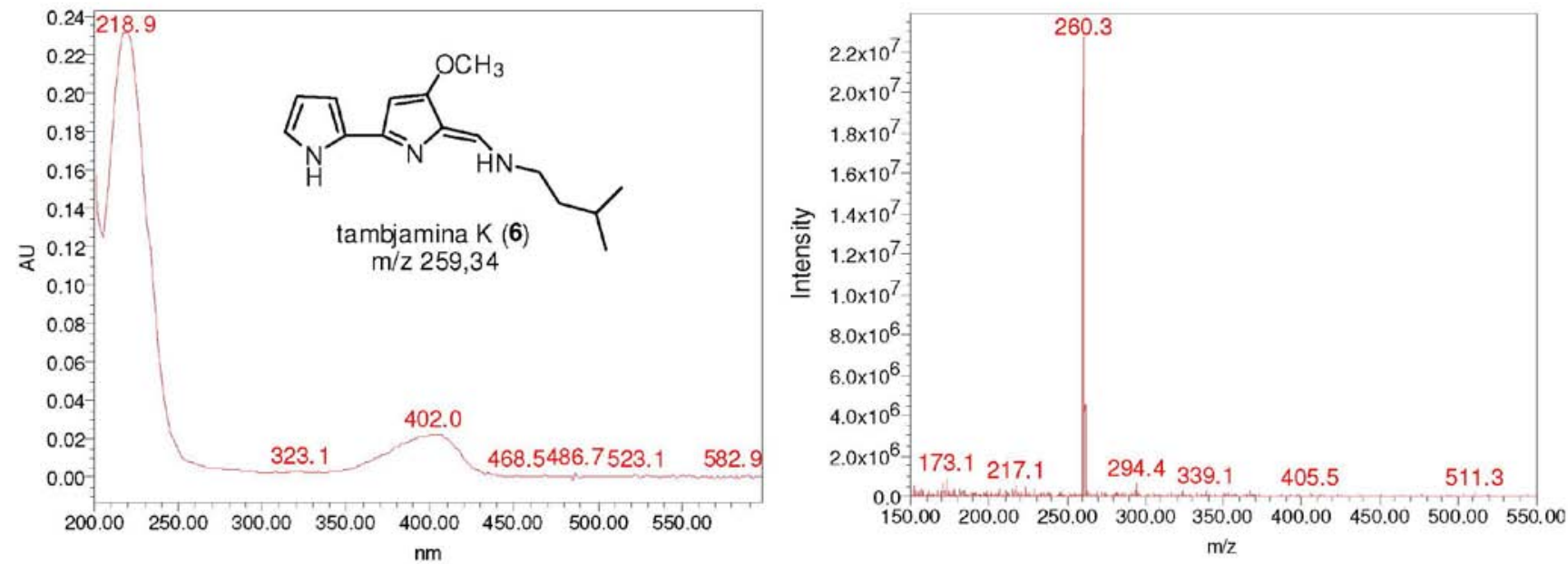

Figura 23S. Espectros no ultravioleta e de massas $\left(\mathrm{ESI}^{+}\right)$da tambjamina $K(\mathbf{6})$ isolada de B. dentata

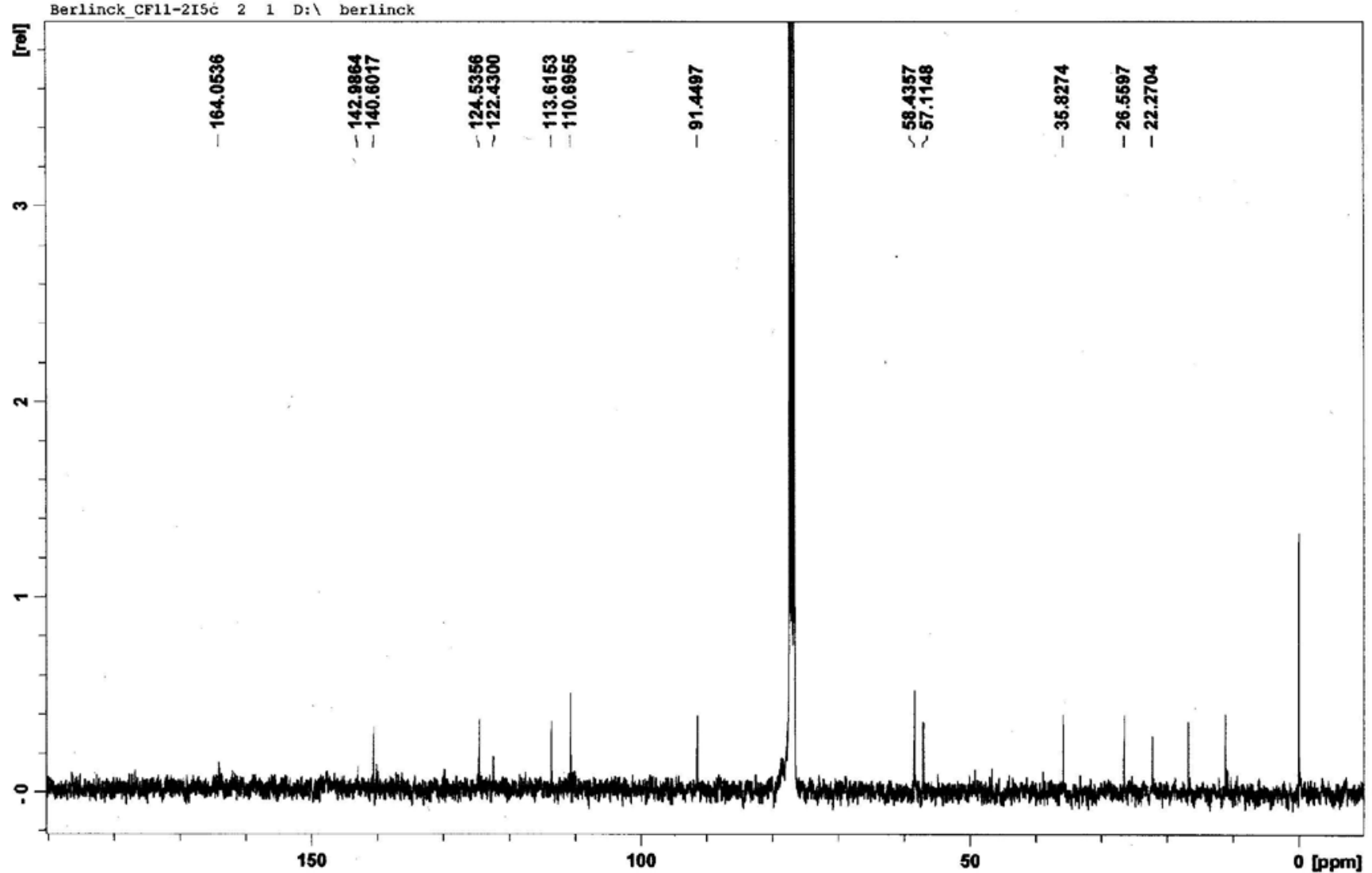

Figura 24S. Espectro de $\mathrm{RMN}^{-1} \mathrm{H}\left(\mathrm{CDCl}_{3}, 400 \mathrm{MHz}\right)$ da tambjamina $\mathrm{K}(6)$ isolada de B. dentata 


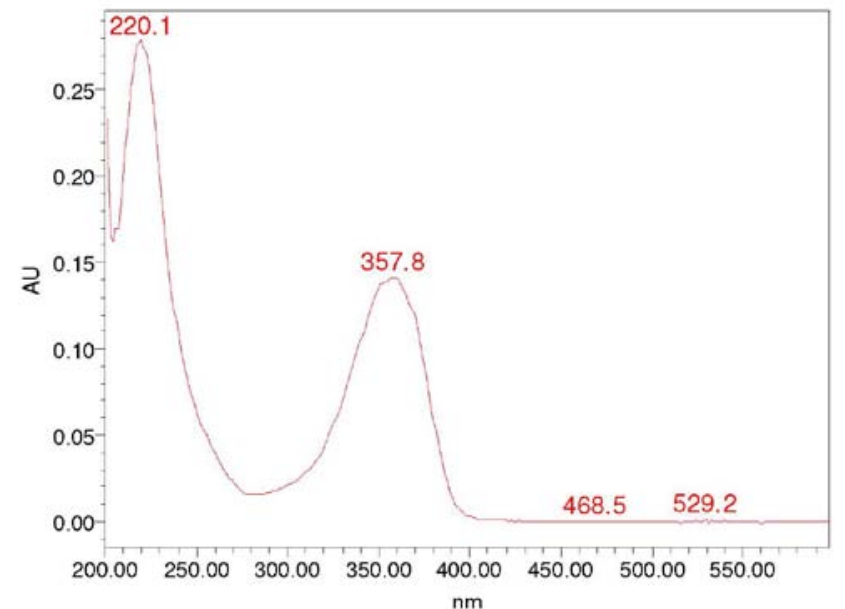

Figura 25S. Espectro de $\mathrm{RMN}_{-}{ }^{13} \mathrm{C}\left(\mathrm{CDCl}_{3}, 100 \mathrm{MHz}\right)$ da tambjamina $\mathrm{K}(6)$ isolada de B. dentata

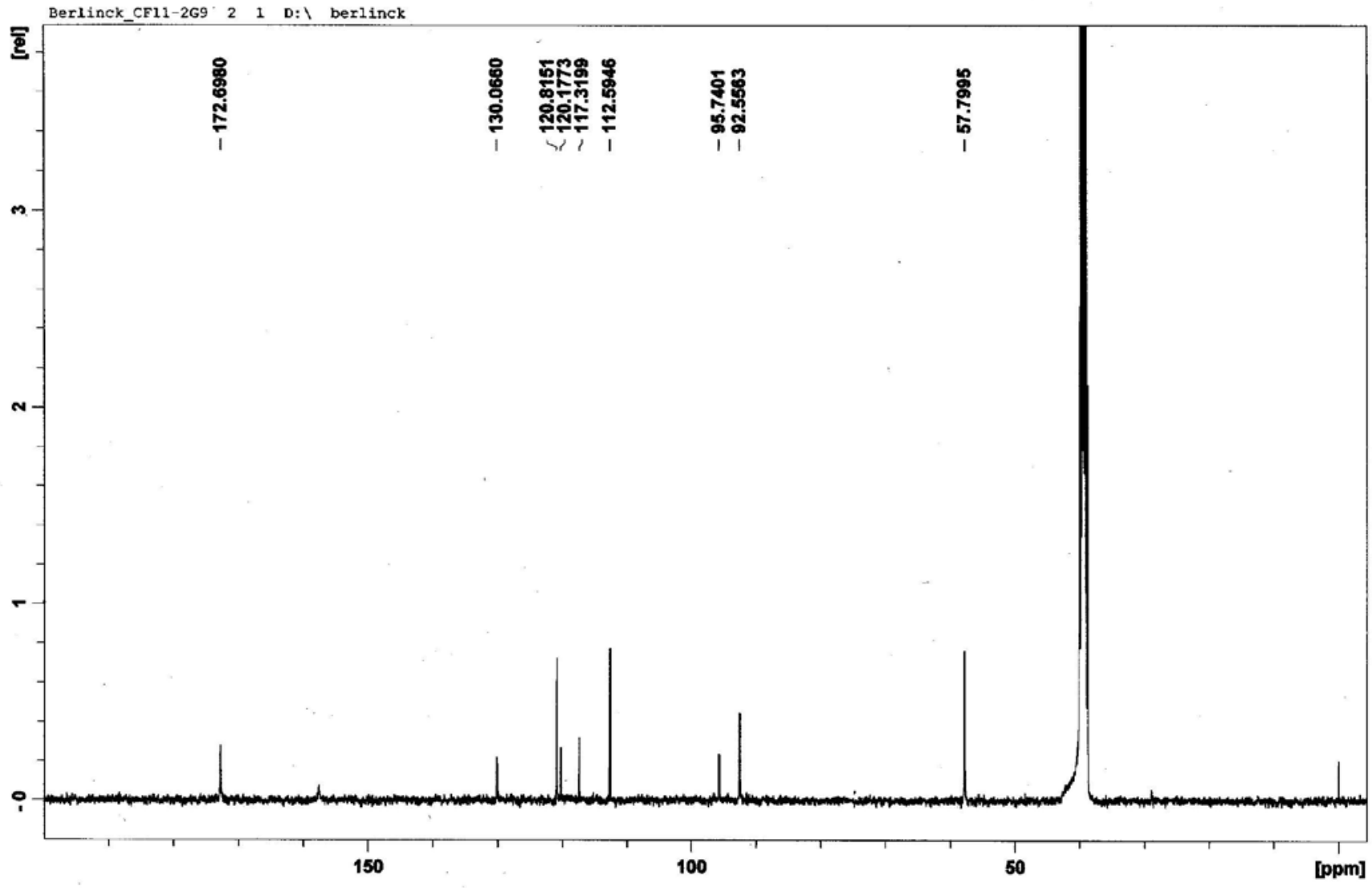

Figura 27S. Espectro de $R M N-{ }^{-1} \mathrm{H}\left(\mathrm{DMSO}-d_{6}, 400 \mathrm{MHz}\right)$ do aldeído da tambjamina B (8) isolada de B. dentata 


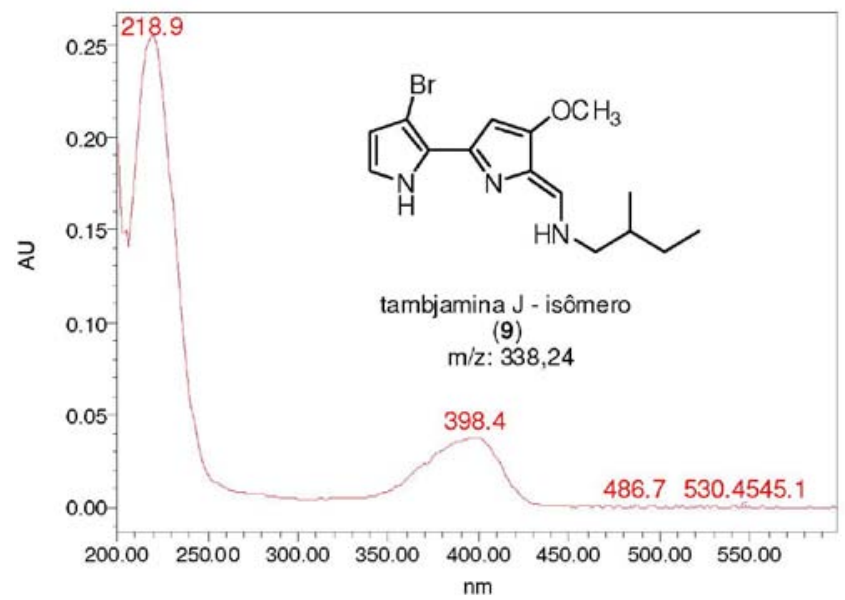

Figura 28S. Espectro de $\mathrm{RMN}-{ }^{13} \mathrm{C}\left(\mathrm{DMSO}-\mathrm{d}_{6}, 100 \mathrm{MHz}\right)$ do aldeído da tambjamina $B(\boldsymbol{8})$ isolada de B. dentata

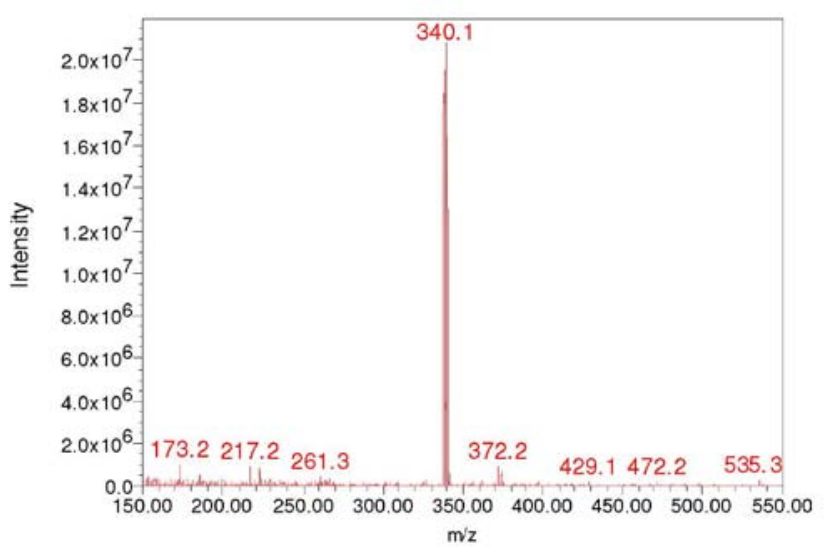

Figura 29S. Espectros no ultravioleta e de massas $\left(\mathrm{ESI}^{+}\right)$da tambjamina JI (9) isolada de B. dentata

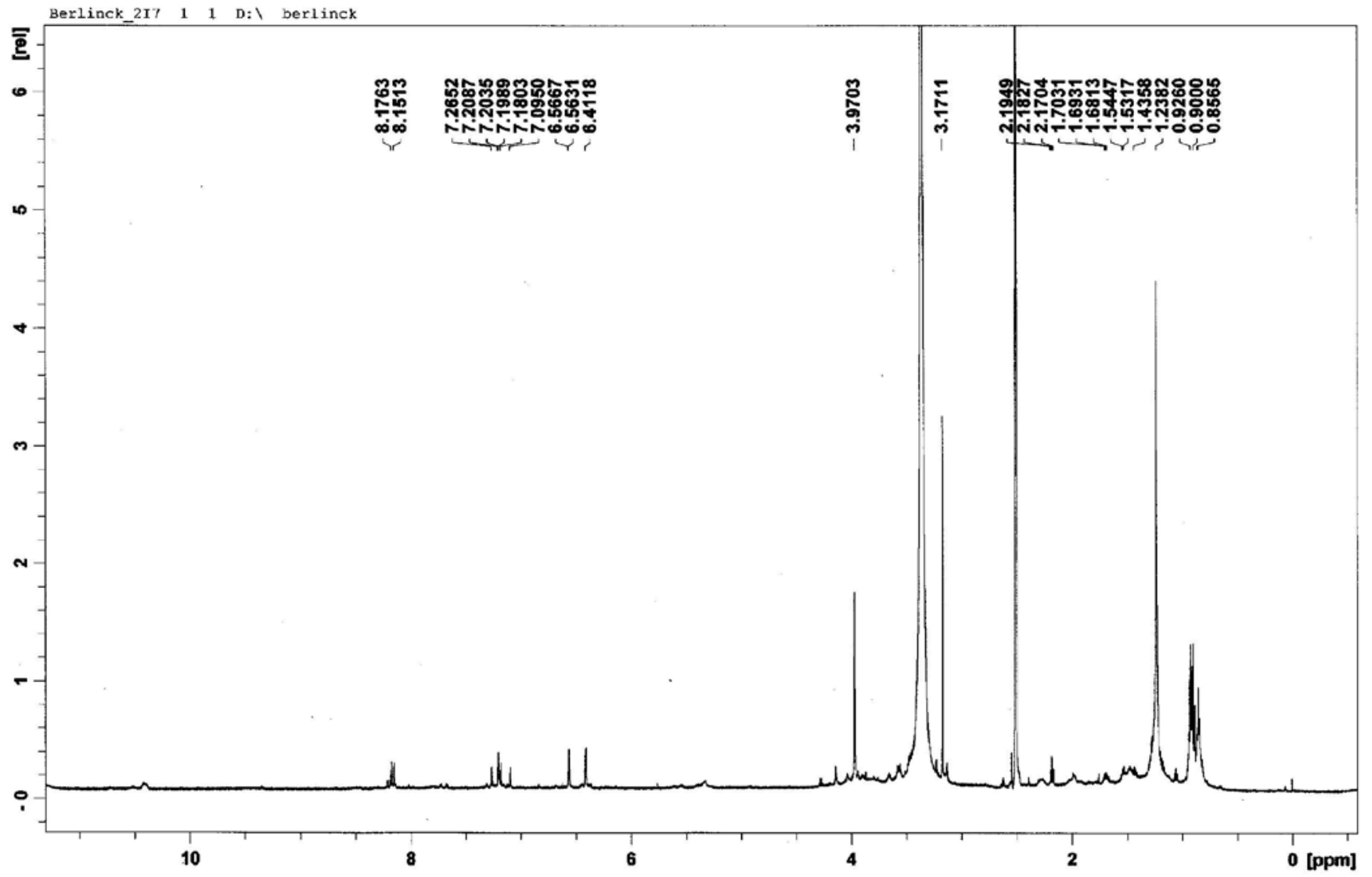

Figura 30S. Espectro de $\mathrm{RMN}^{-1} \mathrm{H}\left(\mathrm{DMSO}-\mathrm{d}_{6}, 600 \mathrm{MHz}\right)$ da tambjamina $\mathrm{J1}$ (9) isolada de B. dentata 


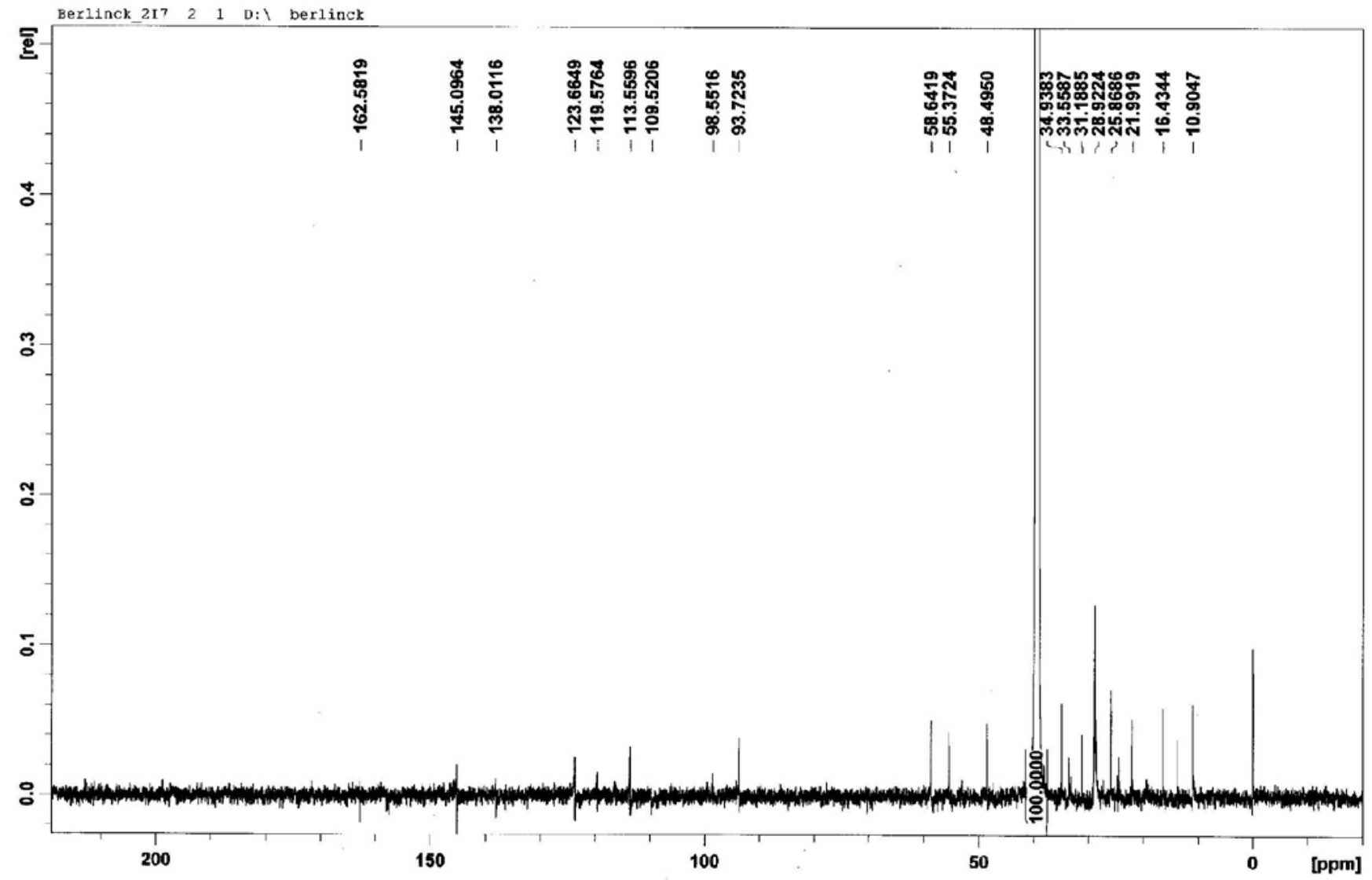

Figura 31S. Espectro de $\mathrm{RMN}^{-13} \mathrm{C}\left(\mathrm{DMSO}-\mathrm{d}_{6}, 150 \mathrm{MHz}\right)$ da tambjamina $\mathrm{J1}$ (9) isolada de B. dentata 

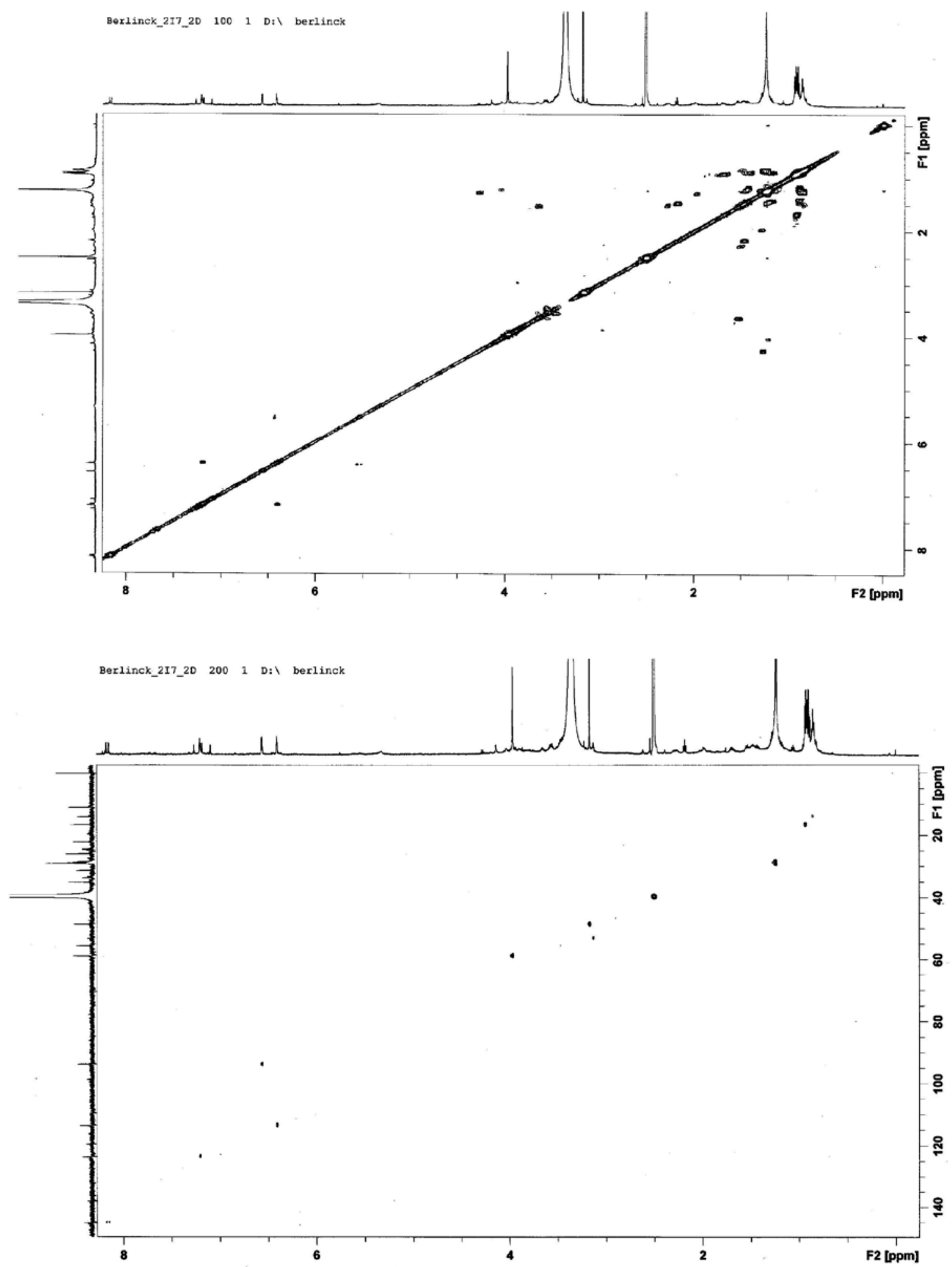

Figura 32S. Espectro de RMN-COSY da tambjamina J1 (9) isolada de B. dentata 


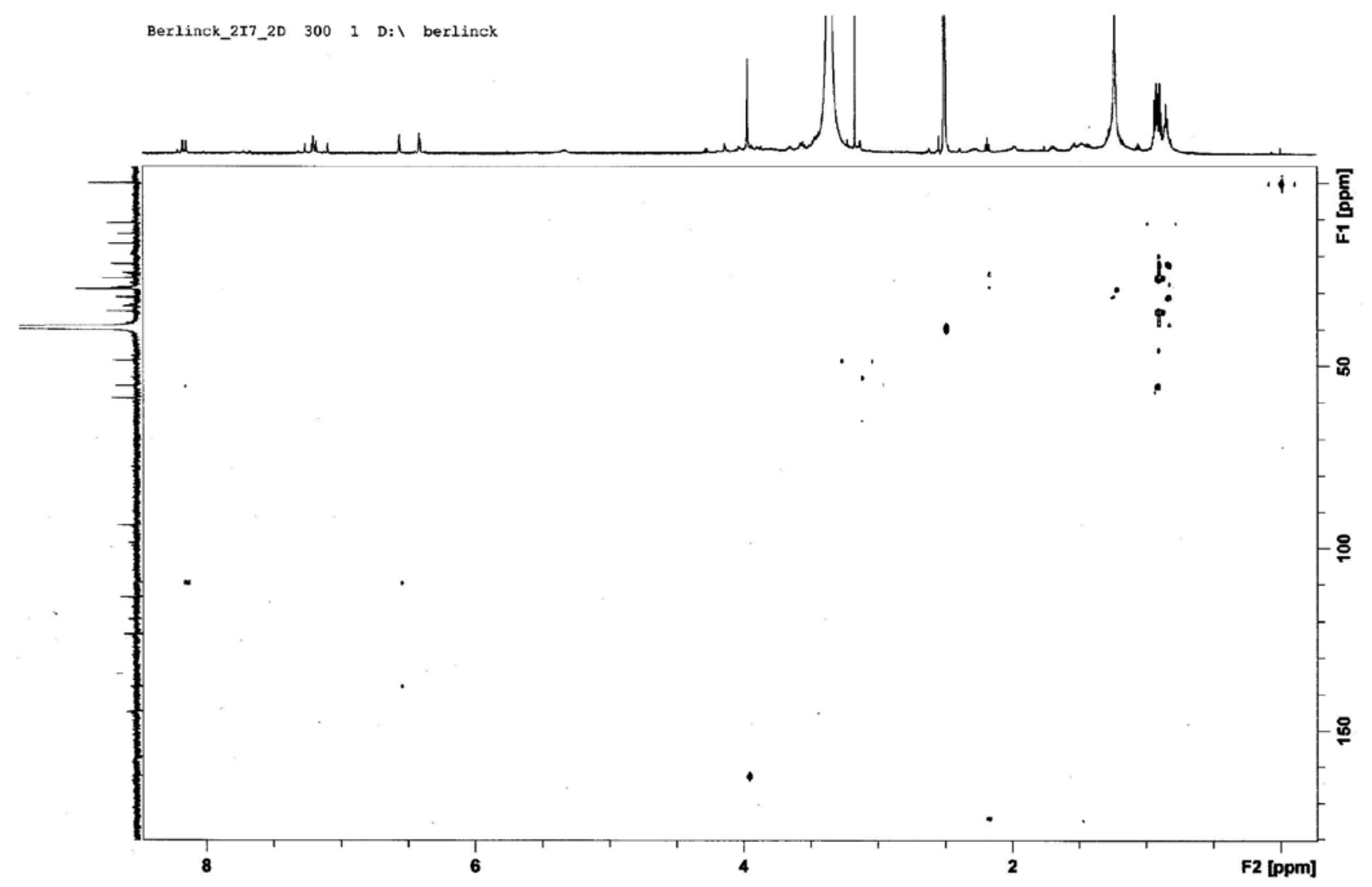

Figura 33S. Espectro de RMN-HSQC da tambjamina J1 (9) isolada de B. dentata

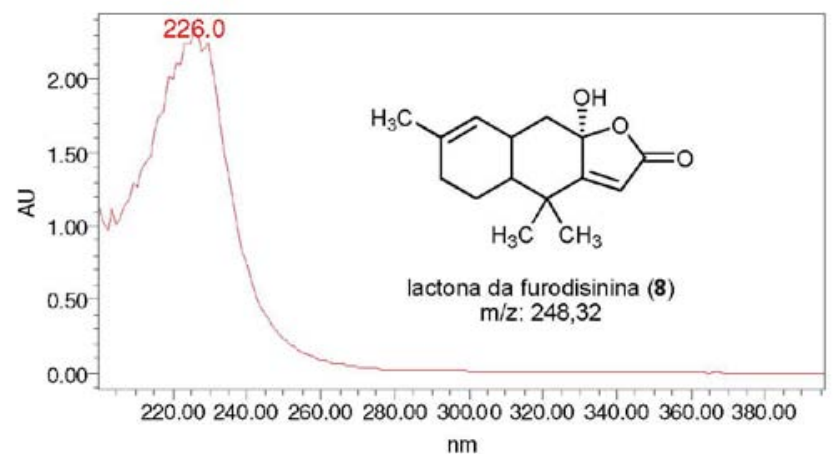

Figura 34S. Espectro de RMN-HMBC da tambjamina J1 (9) isolada de B. dentata 

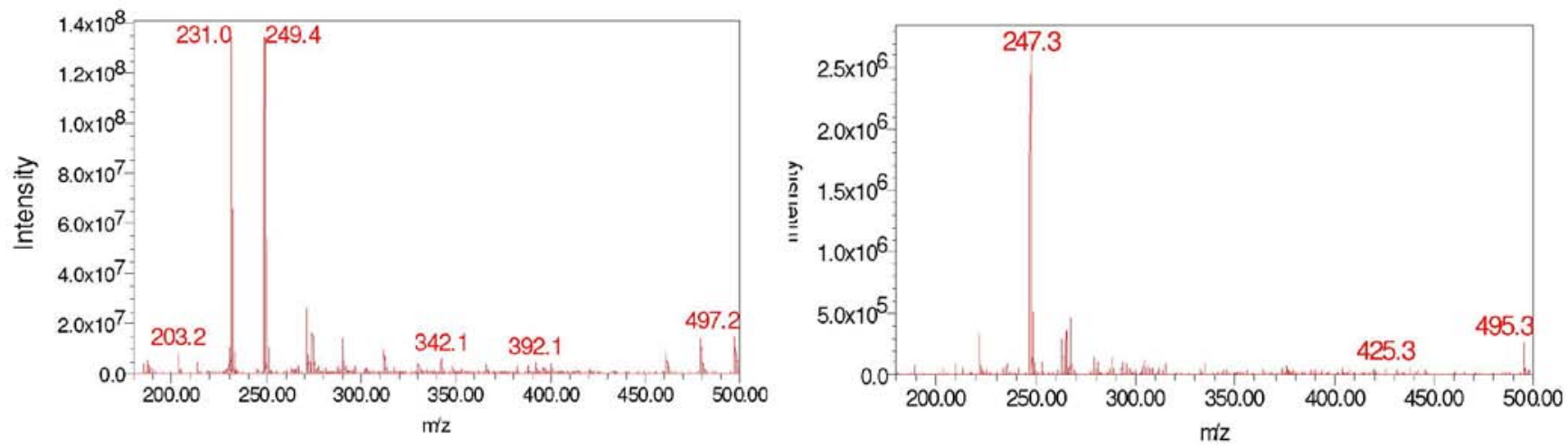

Figura 35S. Espectros no ultravioleta e de massas (ESI+ e ESI-) da lactona da furodisinina (11)

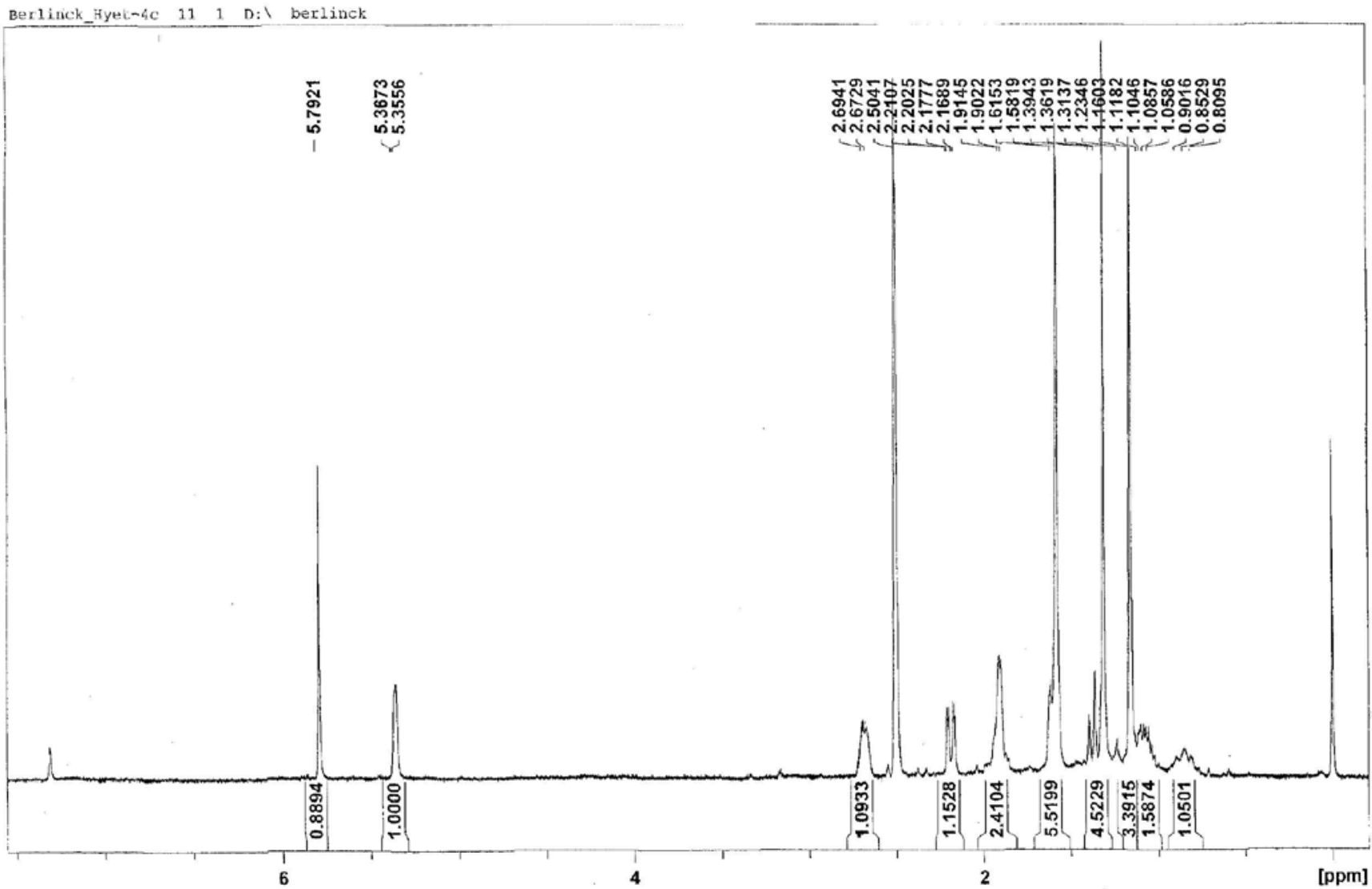

Figura 36S. Espectro de $R M N{ }^{l} H\left(D M S O-d_{6}, 400 \mathrm{MHz}\right)$ da lactona da furodisinina (11) 

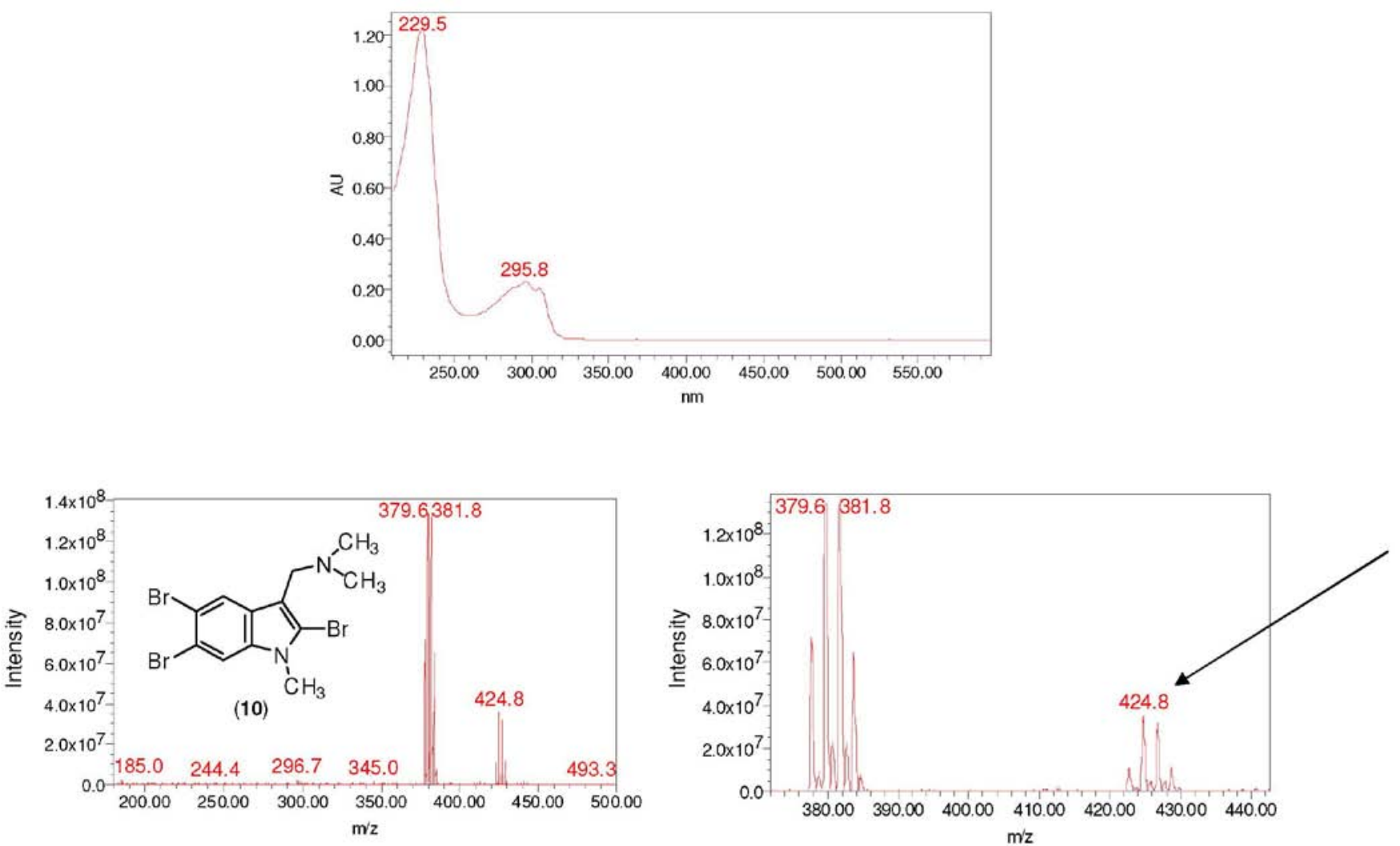

Figura 37S. Espectros no ultravioleta e de massas (ESI+) do 2,5,6-tribromo-N-metilgramina (12)
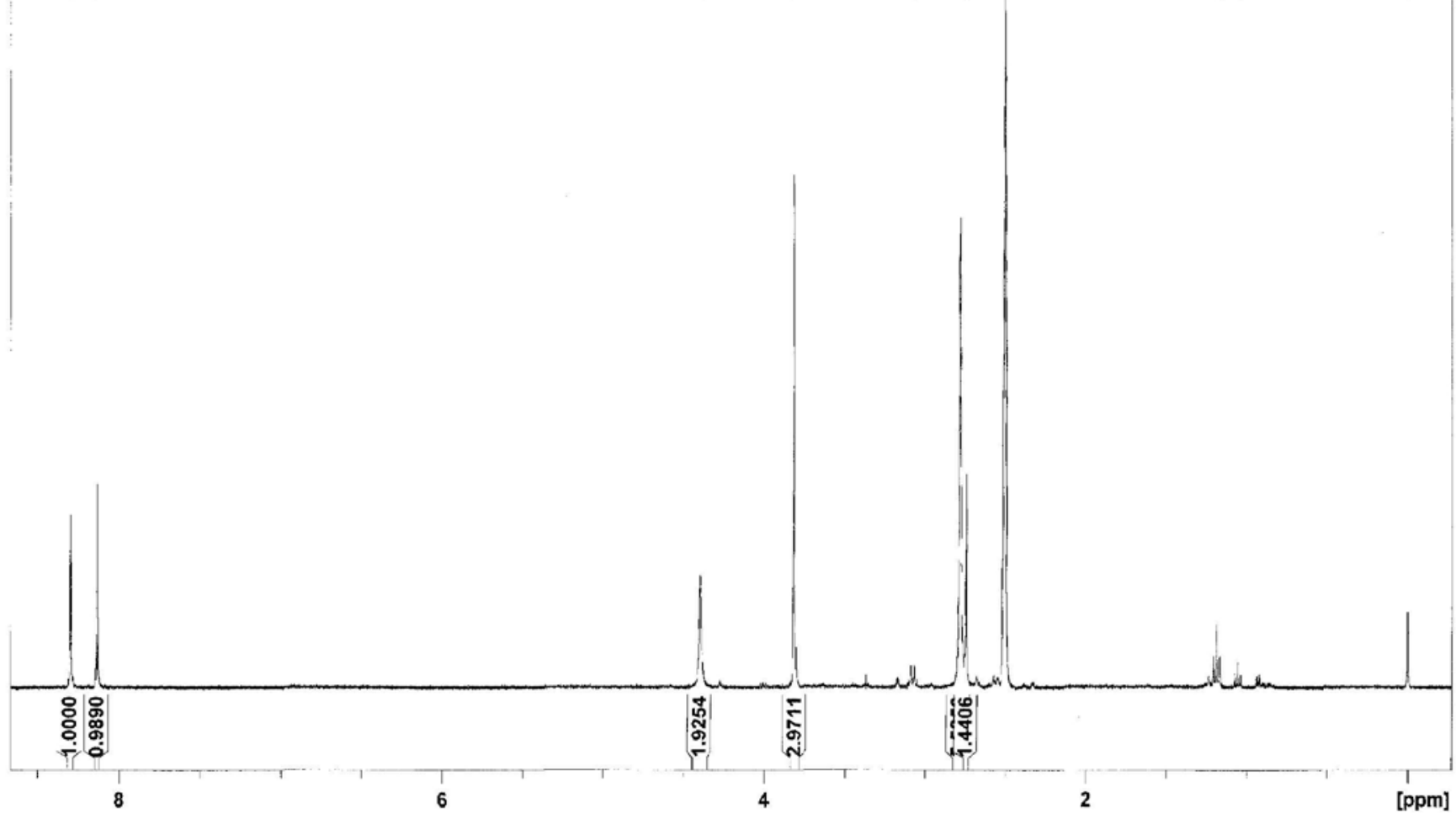

Figura 38S. Espectro de $\mathrm{RMN}^{1} \mathrm{H}\left(\mathrm{DMSO}-\mathrm{d}_{6}, 400 \mathrm{MHz}\right.$ ) 2,5,6-tribromo- $N$-metilgramina (12) 


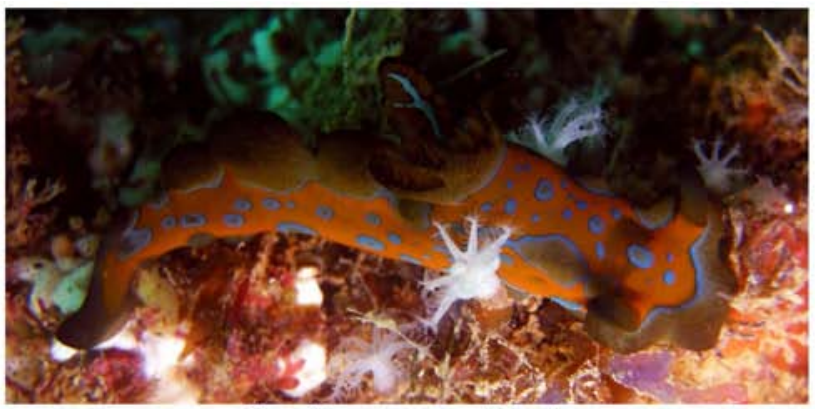

Tambja stegosauriformis

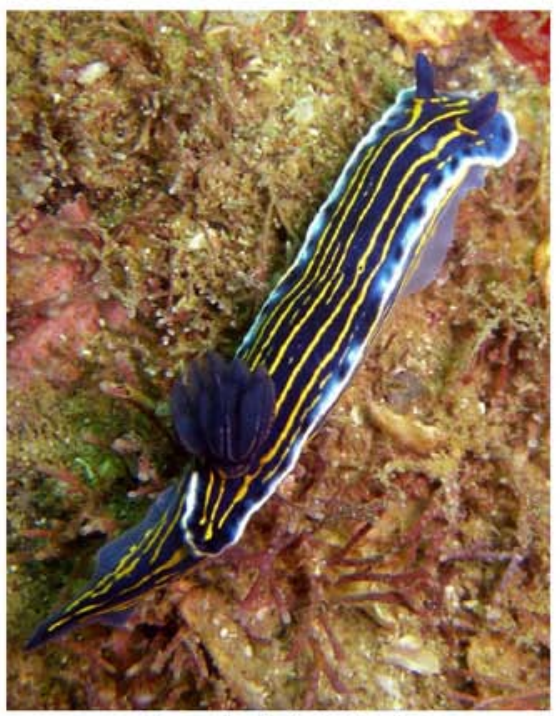

Hypselodoris lajensis

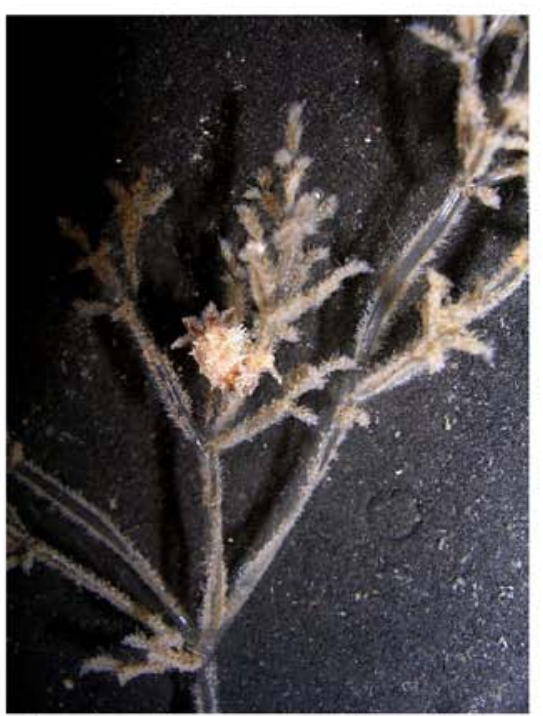

Okenia zoobotryon sobre Z. verticillatum

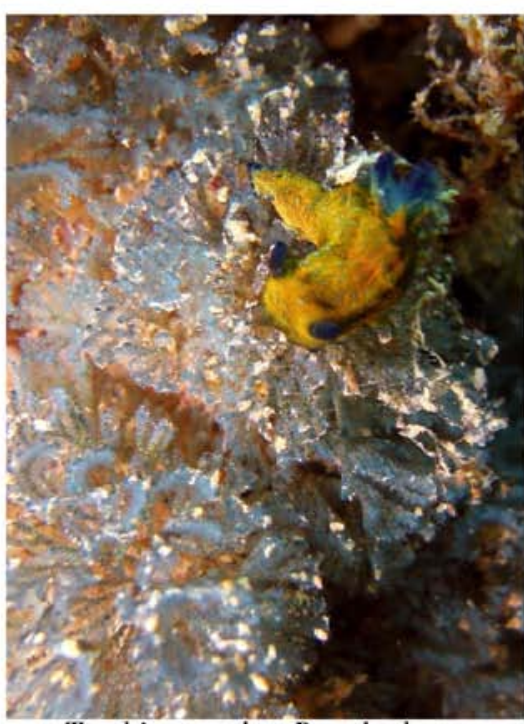

Tambja sp. sobre Bugula dentata

Figura 39S. Fotografias de Tambja stegosauriformis, Hypselodoris lajensis, Okenia zoobotryon sobre Z. verticillatum e Tambja sp. sobre Bugula dentata (fotografias: V. Padula) 